\title{
A distinct D1-MSN subpopulation down-regulates dopamine to promote negative emotional state
}

Zhiyuan Liu ${ }^{1,2}$, Qiumin Le ${ }^{1,2}$, Yanbo Lv ${ }^{1}$, Xi Chen $^{1}$, Jian Cui ${ }^{1}$, Yiming Zhou ${ }^{1}$, Deqin Cheng ${ }^{1}$, Chaonan Ma ${ }^{1}, X_{i u j u a n ~ S u}{ }^{1}$, Lei Xiao ${ }^{1}$, Ruyi Yang ${ }^{1}$, Jiayi Zhang ${ }^{1}$, Lan Ma (iD ${ }^{1 凶}$ and Xing Liu ${ }^{1 凶}$

() The Author(s) 2021

Dopamine (DA) level in the nucleus accumbens (NAC) is critical for reward and aversion encoding. DA released from the ventral mesencephalon (VM) DAergic neurons increases the excitability of VM-projecting D1-dopamine receptor-expressing medium spiny neurons (D1-MSNs) in the NAc to enhance DA release and augment rewards. However, how such a DA positive feedback loop is regulated to maintain DA homeostasis and reward-aversion balance remains elusive. Here we report that the ventral pallidum (VP) projection of NAC D1-MSNs (D1 ${ }^{\text {NAc-VP }}$ ) is inhibited by rewarding stimuli and activated by aversive stimuli. In contrast to the VM projection of D1-MSN (D1 $\left.{ }^{\mathrm{NAc}-\mathrm{VM}}\right)$, activation of $\mathrm{D} 1^{\mathrm{NAc}-\mathrm{VP}}$ projection induces aversion, but not reward. D1 ${ }^{\mathrm{NAc}-\mathrm{VP}}$ MSNs are distinct from the D1 ${ }^{\text {NAc-VM }}$ MSNs, which exhibit conventional functions of D1-MSNs. Activation of D1 ${ }^{\text {NAc-VP }}$ projection stimulates VM GABAergic transmission, inhibits VM DAergic neurons, and reduces DA release into the NAc. Thus, D1 ${ }^{\mathrm{NAc}-\mathrm{VP}}$ and D1 ${ }^{\mathrm{NAc}-\mathrm{VM}}$ MSNs cooperatively control NAc dopamine balance and reward-aversion states.

Cell Research (2022) 32:139-156; https://doi.org/10.1038/s41422-021-00588-5

Emotional valence, the positive (rewarding) or negative (aversive) internal state of an animal, ${ }^{1}$ is fundamental for motivated behavior and reinforcement learning. ${ }^{2}$ Dopamine (DA) is a critical mediator for emotional and motivated behaviors. The nucleus accumbens (NAc), which reciprocally innervates the ventral mesencephalon (VM), including the ventral tegmental area (VTA) and substantia nigra (SNc), has been identified as a critical hub for processing and coding information related to reward and aversion. ${ }^{3-5}$ Up to $95 \%$ of neurons in the NAC are dopaminoceptive GABAergic medium spiny neurons (MSNs). ${ }^{6,7}$ D1-dopamine receptor-expressing MSNs (D1-MSNs) project directly from the NAc to the VM (the direct pathway), or convey information to the VM indirectly through the innervation of the ventral pallidum (VP) (the indirect pathway). D2dopamine receptor-expressing MSNs (D2-MSNs) primarily target VP neurons that innervate the VM (the indirect pathway). ${ }^{8-}$

The prevailing model posits that the activation of D1-MSNs is rewarding and activation of D2-MSNs is aversive. ${ }^{11,12}$ Optogenetic activation of NAC D1-MSNs enhances cocaine-induced conditioned place preference (CPP), whereas optogenetic activation of D2-MSNs suppresses it. ${ }^{13}$ Chemogenetic inhibition of NAC D2MSNs augments cocaine seeking. ${ }^{14}$ It has been demonstrated that DA release in the NAc activates both D1- and D2-dopamine receptors, and increases CAMP/PKA activity in D1-MSNs and inhibits CAMP/PKA activity in D2-MSNs. ${ }^{15,16}$ Then DA binding to D1- and D2-receptors enhances excitability of D1-MSNs and decreases the excitability of D2-MSNs through the regulation of cAMP/PKA signaling. ${ }^{15,17}$ It was well known that activation of D1 receptor and inactivation of D2 receptors in the NAc produces opposing behavioral effects. ${ }^{18}$ DA release induced activation of
D1-MSNs and inhibition of D2-MSNs synergistically augment DA release in the NAc and promote greater reward. ${ }^{19}$ How is this positive feedback loop of DA release and reward regulated? Is there a negative feedback or brake mechanism?

In the current study, we show that activation of VM- and VP-projections of NAc D1-MSNs (D1 ${ }^{\text {NAc-VM }}$ and D ${ }^{\text {NAc-VP }}$ pathways) is elicited by stimuli of different valences and produces opposing behavioral responses. Contradicting to the conventional role of D1-MSNs, the D1 ${ }^{\text {NAc-VP }}$ projection is suppressed by a rewarding stimulus and activated by an aversive stimulus, and activation of D1 ${ }^{\text {NAc-VP }}$ pathway mediates aversive, but not reward response. We also reveal that VP and VM projecting D1-MSNs are two largely separate populations of neurons. Our data indicate that $D 1^{\mathrm{NAc}-\mathrm{VP}}$ and $D 1^{N A c-V M}$ projection neurons encode opposing emotional valences via differential regulation of VM DAergic neurons and NAc DA release, cooperatively modulating reward-aversion state.

\section{RESULTS}

Negative stimulus induces activation of $D 1^{\text {NAc-VP }}$ projection and concurrent suppression of $D 1^{N A c-V M}$ projection, while positive stimulus suppresses $D 1^{\text {NAc-VP }}$ projection and concurrently activates D1 ${ }^{\text {NAc-VM }}$ projection

To explore the potential roles of projections of NAc D1-MSNs to VM and VP, we first examined their responses to stimuli of positive and negative valences. We expressed GCaMP in the accumbal D1MSNs and recorded calcium transient in their projections in the VM and VP (Fig. 1a, b). As shown in Fig. 1c, the photometry recording showed that the onset of sucrose licking as detected by

${ }^{1}$ Department of Neurosurgery, Huashan Hospital, School of Basic Medical Sciences, and Institutes of Brain Science, State Key Laboratory of Medical Neurobiology and MOE Frontiers Center for Brain Science, Fudan University, Shanghai, China. ${ }^{2}$ These authors contributed equally: Zhiyuan Liu, Qiumin Le. ${ }^{\circledR}$ email: lanma@fudan.edu.cn; xingliu@fudan.edu.cn 


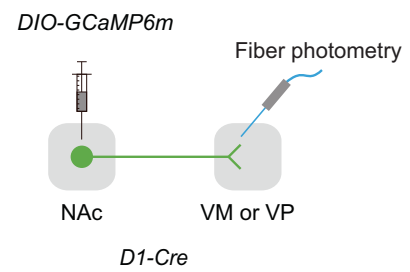

c

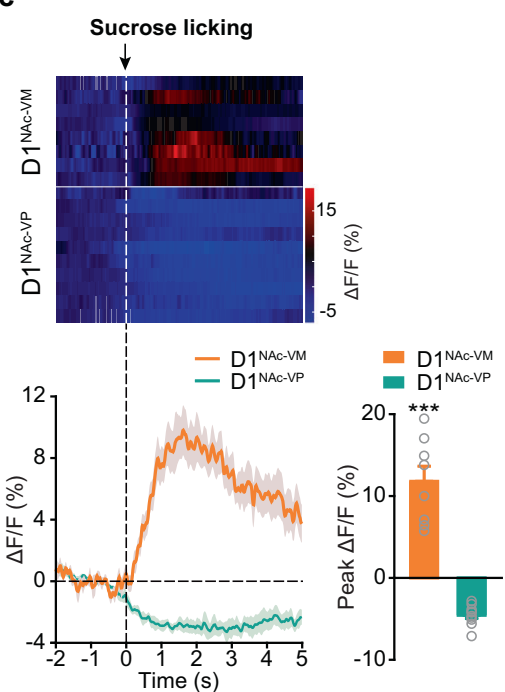

f
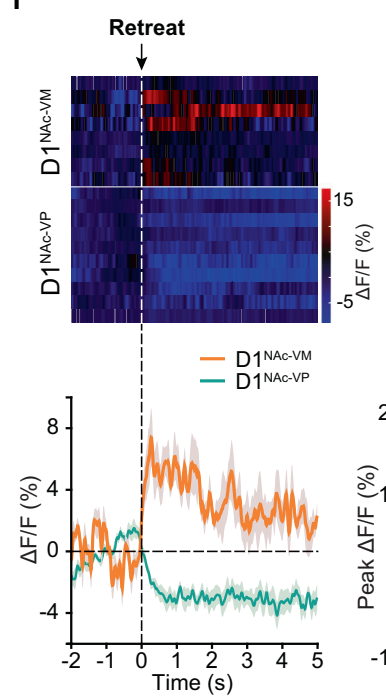

b
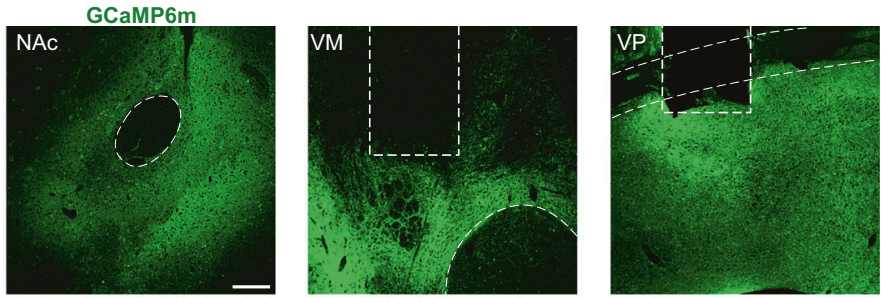

d

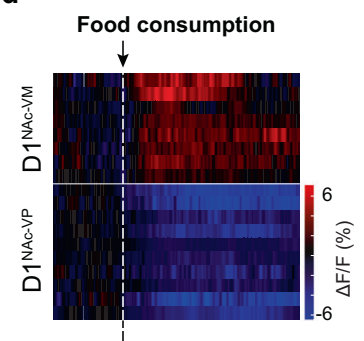

e
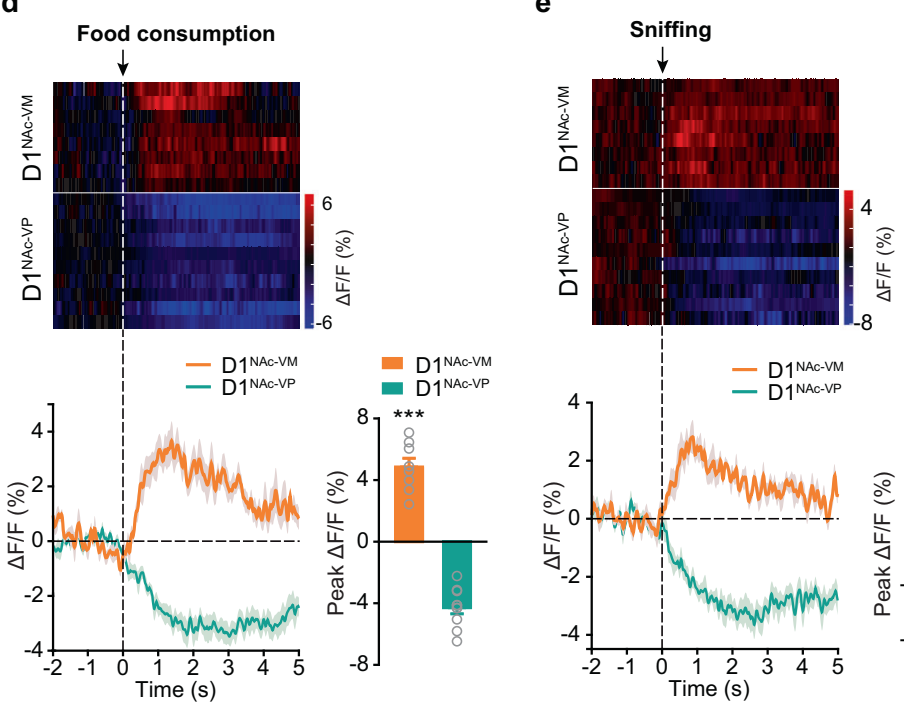

g
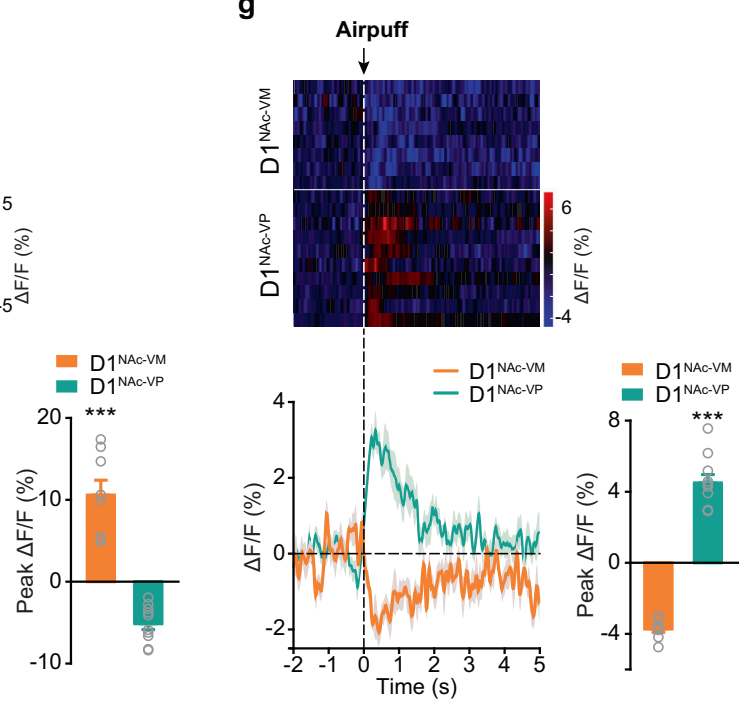

h

Tail suspension Release
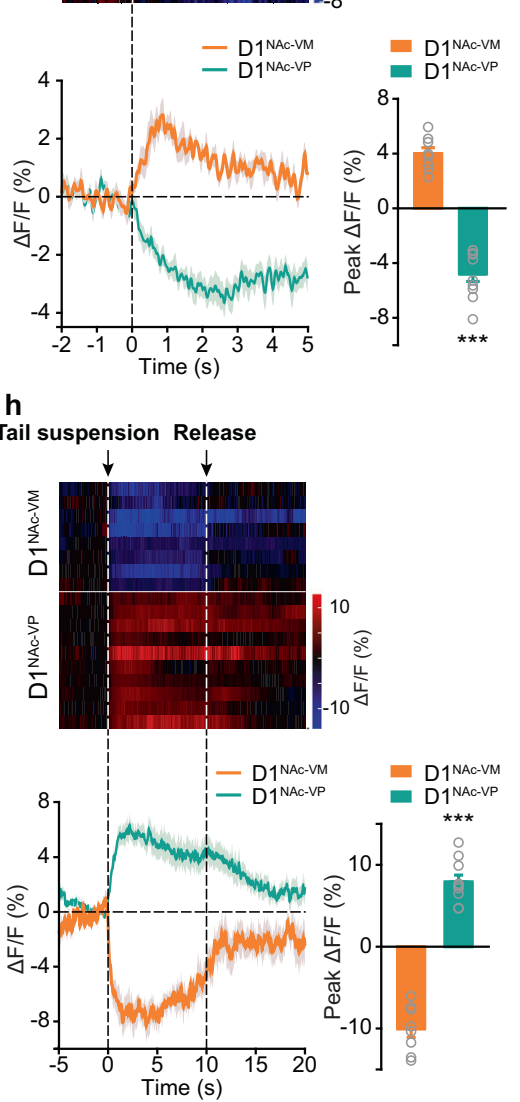

Fig. 1 Rewarding and aversive stimuli induce opposing responses in D1 ${ }^{\text {NAc-VM }}$ and D1 ${ }^{\text {NAc-VP }}$ projections. a Strategy for recording calcium activity of $D 1^{\mathrm{NAc}-\mathrm{VM}}$ or $\mathrm{D} 1^{\mathrm{NAc}-\mathrm{VP}}$ projections in response to stimuli in freely moving mice. AAV ${ }_{9}-E F 1 a-D I O-G C a M P 6 m$ was injected into the NAc of D1-Cre mice, with optical fiber implanted over the VM or VP. b Representative images showing GCaMP ${ }^{+}$terminals in the VM and VP. Scale bar: $100 \mu \mathrm{m}$. c-h Heat map (Top), plot and statistical graph (Bottom) of group average GCaMP responses aligned to the onset of sucrose licking (c), sucrose pellet consumption (d), sniffing of female stranger (e), retreat from the novel object in approachavoidance task (f), air puff $(\mathbf{g})$, or tail suspension $(\mathbf{h})$. In sucrose licking and consumption task, $\mathrm{Ca}^{2+}$ signal was recorded when mice were licking and chewing pellet. In approach-avoidance task, when mice encountered a novel object, they approached and explored, and then quickly retreated from it. $\mathrm{Ca}^{2+}$ signal was recorded during an approach and a quick retreat followed. In social interaction task, $\mathrm{Ca}^{2+}$ signal was recorded during chasing and sniffing the stranger female. In air puff and tail suspension tasks, Ca ${ }^{2+}$ signal was recorded when the air puff was unexpectedly delivered to the eye and the tail was unexpectedly lifted. Bar graph: Quantification of peak amplitude of $\mathrm{Ca}^{2+}$ events to and after the onset of sucrose licks, sucrose pellet consumption, sniffing, retreat, air puff, or tail suspension [Mann-Whitney U test: $c$ D $1^{\text {NAc-VM }} n=8, \mathrm{D} 1^{\text {NAc-VP }} n=10, Z=-3.554, P=0.000046 ; f_{D} 1^{\text {NAc-VM }} n=8, D 1^{\text {NAc-VP }} n=10, Z=-3.554, P=$ 0.000046 ; Two-tailed Student's $t$-test: d D1 ${ }^{\mathrm{NAc}-\mathrm{VM}} n=8, \mathrm{D} 1^{\mathrm{NAc}-\mathrm{VP}} n=10, t(16)=13.552, P<0.001$; e D $1^{\mathrm{NAc}-\mathrm{VM}} n=8, \mathrm{D} 1^{\mathrm{NAc}-\mathrm{VP}} n=10, t(16)=$ $12.049, P<0.001 ; \mathrm{g} \mathrm{D} 1^{\mathrm{NAc}-\mathrm{VM}} n=8, \mathrm{D} 1^{\mathrm{NAc}-\mathrm{VP}} n=10, t(16)=-14.66, P<0.001 ; \mathbf{h}^{\mathrm{D}} 1^{\mathrm{NAc}-\mathrm{VM}} n=8, \mathrm{D} 1^{\mathrm{NAc}-\mathrm{VP}} n=10, t(16)=-13.856$, $P<0.001.]{ }^{* * *} P<0.001$. 
lickometer in water-restricted mice triggered an increase of GCaMP fluorescence in $\mathrm{D} 1^{\mathrm{NAc}-\mathrm{VM}}$ projection in the $\mathrm{VM}$, but a decrease of GCaMP signal in D1 ${ }^{\mathrm{NAc}-V P}$ projection in the VP (Fig. 1c). To minimize the possible effect of stress factors resulted from water or food retraction, the response of these two projections to palatable food consumption was examined. Consistent with the result of sucrose liking, increased GCaMP fluorescence in D1 ${ }^{\mathrm{NAc}-\mathrm{VM}}$ projection and decreased GCaMP signal in $\mathrm{D} 1^{\mathrm{NAc}-\mathrm{VP}}$ projection were detected during sucrose pellet consumption (Fig. 1d). Social interaction with a female stranger is a natural reward to male adults. We found that during social behavioral tests, sniffing the female stranger increased calcium activity in $\mathrm{D} 1^{\mathrm{NAc}-\mathrm{VM}}$ projection, but decreased calcium signal in D1 ${ }^{\mathrm{NAc}-\mathrm{VP}}$ projection (Fig. 1e). These data indicate that natural reward stimuli induce opposing responses in $\mathrm{D} 1^{\mathrm{NAc}-\mathrm{VM}}$ and $\mathrm{D} 1^{\mathrm{NAc}-\mathrm{VP}} \mathrm{MSNs}$, causing activation of $D 1^{\text {NAc-VM }}$ and suppression of D1 ${ }^{\text {NAc-VP }}$ MSNs. Safety is regarded as positive valence and encoded by dopamine neurons. ${ }^{20}$ In approach-avoidance task, when mice encounter a novel object in a familiar environment, they typically approach and explore it due to fear and curiosity, and then quickly retreat from it. Retreat produces safety and reinforcement signal. ${ }^{21-23}$ We observed that when mice began to retreat from the novel object in the center of the open field, GCaMP fluorescence increased rapidly in D1 NAc-VM projection, but dropped in D1 $1^{\text {NAc-VP }}$ projection (Fig. 1f), confirming that stimuli of positive valence activate D1 ${ }^{\text {NAc-VM }}$ MSNs while inhibit D1 ${ }^{\text {NAc-VP }}$ MSNs. We speculate that D1 $1^{\text {NAc-VM }}$ and D1 ${ }^{\text {NAc-VP }}$ MSNs may be involved in encoding positive and negative valences, respectively.

Next acute stressors including air puff and tail suspension ${ }^{24,25}$ were introduced as the stimuli of negative valence. In contrast to the response to a natural reward, air puff caused a decrease in GCaMP fluorescence intensity in D1 $1^{\text {NAc-VM }}$ projection and an increase in $D 1^{\text {NAc-VP }}$ projection (Fig. 1g). Similarly, during tail suspension test, we observed a decrease in GCaMP signal in D1 ${ }^{\mathrm{NAc}-\mathrm{VM}}$ and an increase in $D 1^{\text {NAc-VP }}$ projections when mice were chased and lifted by hand (Fig. 1h). After mice were released, GCaMP fluorescence returned to the baseline. Control mice expressing eGFP in D1-MSNs showed no significant change in GCaMP fluorescent intensity during these stimulus-induced conditions, suggesting that the observed changes in calcium activity were not movement artifacts (Supplementary information, Fig. S1). Our results show that positive stimuli increase the activity of $D 1^{\text {NAc-VM }}$ projection and decrease the activity of $\mathrm{D1}{ }^{\mathrm{NAC}-\mathrm{VP}}$ projection; while negative stimuli decrease the activity of $\mathrm{D} 1^{\mathrm{NAc}-\mathrm{VM}}$ projection and increase the activity of $\mathrm{D} 1^{\mathrm{NAc}-\mathrm{VP}}$ projection. These data demonstrate that $\mathrm{D} 1^{\mathrm{NAc}-\mathrm{VM}}$ and $\mathrm{D} 1^{\mathrm{NAc}-\mathrm{VP}}$ projections are activated by stimuli of opposite valences and the stimulus induced activation of one projection is concurrent with suppression of another projection. Thus, $\mathrm{D} 1^{\mathrm{NAc}-\mathrm{VM}}$ and $\mathrm{D} 1^{\mathrm{NAc}-\mathrm{VP}}$ projections may bi-directionally and cooperatively regulate responses to rewarding and aversive stimuli.

\section{Activation of D1 $1^{\text {NAc-VM }}$ and D1 ${ }^{\text {NAc-VP }}$ projections lead to opposite emotional states}

Based on the above results, we raise the question of whether activation of $\mathrm{D} 1^{\mathrm{NAc}-\mathrm{VP}}$ projection induces the same emotional states as activation of $D 1^{\mathrm{NAc}-\mathrm{VM}}$ projection does. We conditioned mice by laser stimulation of $\mathrm{D} 1^{\mathrm{NAc}-\mathrm{VM}}$ or $\mathrm{D} 1^{\mathrm{NAc}-\mathrm{VP}}$ projection in a place preference apparatus (Fig. 2a). As expected, after laser conditioning, D1 ${ }^{\mathrm{NAc}-\mathrm{VM}}:$ ChR2 mice developed a preference for the laser side (Fig. 2b, c; Supplementary information, Fig. S2a); however, D1 ${ }^{\mathrm{NAc}-\mathrm{VP}}:$ ChR2 mice, on the contrary, exhibited a significant aversion to the laser side (Fig. 2d, e). Consistently, D1 ${ }^{\text {NAc-VM }}$ :eNpHR3.0 mice showed a place aversion (Fig. $2 f$, $g_{i}$ Supplementary information, Fig. S2b), and D1 ${ }^{\text {NAc-VP: }}$ :eNpHR3.0 mice developed a preference for the laser conditioned side (Fig. $2 \mathrm{~h}, \mathrm{i})$. These data indicate that activation of $\mathrm{D} 1^{\mathrm{NAc}-\mathrm{VP}}$ projection promotes aversive emotion, opposite to the rewarding effect by activation of $\mathrm{D} 1^{\mathrm{NAc}-\mathrm{VM}}$ projection.
Emotional valence is crucial for reinforcement learning. We expressed ChR2 in D1-MSNs, then performed optogenetically intracranial self-stimulation assay (ICSS), intracranial light administration in specific subarea assay (ICLASS), and real-time place preference/avoidance (RTPP/A) task, in which an active nose poke or entering the defined area would trigger laser stimulation of $\mathrm{D} 1^{\mathrm{NAc}-\mathrm{VM}}$ or $\mathrm{D} 1^{\mathrm{NAc}-\mathrm{VP}}$ projection (Fig. $2 \mathrm{j}-\mathrm{t}$ ). In ICSS task, we observed a robust increase of active nose poke coupled to optogenetic activation of D1 ${ }^{\text {NAc-VM }}$ projection, and a significantly reduced nose poke coupled to optogenetic activation of D1 ${ }^{\mathrm{NAc}-\mathrm{VP}}$ projection (Fig. 2j-I). In ICLASS task, optogenetic activation of $D 1^{N A c-V M}$ projection when mice stayed in the center extended the duration in the center area, while optogenetic activation of $D 1^{N A c-V P}$ projection when they stayed in the periphery reduced time spent in this area (Fig. 2m-p). Consistently, in the RTPP/A task, optogenetic activation of $\mathrm{D} 1^{\mathrm{NAc}-\mathrm{VM}}$ projection induced the preference for the laser stimulation side, while optogenetic activation of $\mathrm{D} 1^{\mathrm{NAc}-\mathrm{VP}}$ projection induced avoidance for the laser side (Fig. $2 q-t)$. These results indicate that activation of $D 1^{N A c-V M}$ projection drives positive reinforcement and activation of $D 1^{\mathrm{NAc}-\mathrm{VP}}$ projection promotes negative reinforcement.

To further confirm the roles of these two projections in the regulation of emotional states, we applied optogenetic stimulation of these projections in cocaine-induced reward and $\mathrm{LiCl}$-induced aversion models (Fig. 3a). The data showed that optogenetic inhibition of $\mathrm{D} 1^{\mathrm{NAc}-\mathrm{VM}}$ projection and optogenetic activation of $\mathrm{D} 1^{\mathrm{NAc}-\mathrm{VP}}$ projection during cocaine conditioning could both reduce cocaine CPP (Fig. 3b-e), and optogenetic inhibition of D1 $1^{\text {NAc-VP }}$ projection and optogenetic activation of $\mathrm{D} 1^{\mathrm{NAc}-\mathrm{VM}}$ projection during $\mathrm{LiCl}$ conditioning could both suppress $\mathrm{LiCl}$ CPA (Fig. 3f-i). Moreover, when the mice were conditioned with stimulation of $D 1^{N A c-V M}$ projection on one side and injection of cocaine on the other side of the CPP chamber, they showed no preference for either side (Supplementary information, Fig. S3a, b), confirming that activation of $\mathrm{D} 1^{\mathrm{NAC}-\mathrm{VM}}$ projection produces comparable rewarding effects as cocaine injection. In CPA test, mice conditioned with stimulation of $\mathrm{D} 1^{\mathrm{NAc}-\mathrm{VP}}$ projection on one side and $\mathrm{LiCl}$ injection on the other side exhibited $\sim 40 \%$ reduced aversion to the optical stimulation side compared with stimulation of D1 $1^{\text {NAc-VP }}$ projection alone (Supplementary information, Fig. S3c, d), suggesting the aversion produced by direct activation of $\mathrm{D} 1^{\mathrm{NAc}-\mathrm{VP}}$ projection is stronger than that evoked by systematic injection of $\mathrm{LiCl}$. These data further demonstrate that activation of $\mathrm{D} 1^{\mathrm{NAc}-\mathrm{VP}}$ projection or inhibition of $\mathrm{D} 1^{\mathrm{NAc}-\mathrm{VM}}$ projection induces aversion, while activation of D1 ${ }^{\mathrm{NAc}-\mathrm{VM}}$ projection or inhibition of $\mathrm{D} 1^{\mathrm{NAc}-\mathrm{VP}}$ projection promotes reward, indicating that these two projections drive opposing valence states and may cooperatively regulate rewarding and aversion.

Next, we did photometry recording of $\mathrm{Ca}^{2+}$ transient of $\mathrm{D} 1^{\mathrm{NAc}-\mathrm{VM}}$ and $\mathrm{D} 1^{\mathrm{NAC}-\mathrm{VP}}$ projections during the test phase of cocaine CPP and optical stimulation-induced CPP/A (Fig. 3j-q). The overall frequency of $\mathrm{Ca}^{2+}$ transient events in VM and VP axonal terminals of D1-MSNs was both significantly elevated during cocaine conditioning (Supplementary information, Fig. S3e-i). In cocaine CPP test, the GCaMP signal was increased in D1 ${ }^{\text {NAc-VM }}$ projection and decreased in $D 1^{\mathrm{NAc}-\mathrm{VP}}$ projection when mice entered the cocaine-paired side (Fig. 3j-m). Moreover, during test of CPP/A induced by stimulation of ChR2 expressing D1 $1^{\text {NAc-VM }}$ or D1 ${ }^{\text {NAc-VP }}$ projection, the GCaMP signal in $\mathrm{D} 1^{\mathrm{NAc}-\mathrm{VM}}$ projection was increased when mice that had acquired CPP entered the stimulation-paired side (Fig. 3n-p), and the GCaMP signal in D1 ${ }^{\text {NAc-VP }}$ projection was increased when mice that had acquired CPA entered the stimulation-paired side (Fig. 3q).

\section{VP- and VM-projecting NAC D1-MSNs exhibit distinct anatomic, molecular, and electrophysiological properties} To definitively examine the anatomical organization of D1 NAc-VM and D1 $1^{\text {NAc-VP }}$ projectors, we used cholera-toxin subunit $B(C T B)$ to label D1 ${ }^{\text {NAc-VM }}$ and D1 $1^{\text {NAc-VP }}$ neurons in individual mouse as previously reported. ${ }^{26}$ We injected CTB488 into the VP and CTB647 


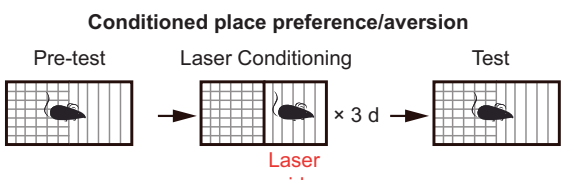

b

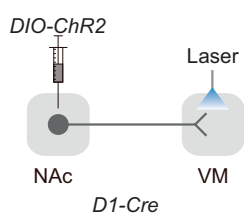

d

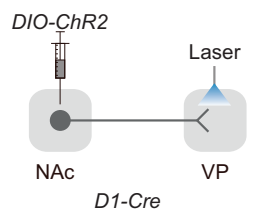

f

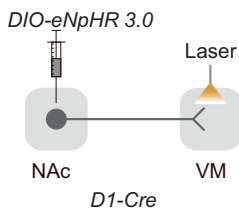

h

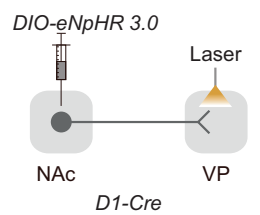

j

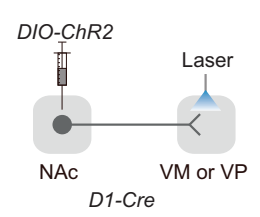

m

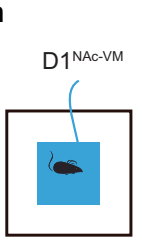

ICLASS

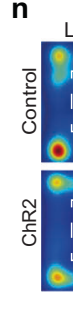

RTPPIA
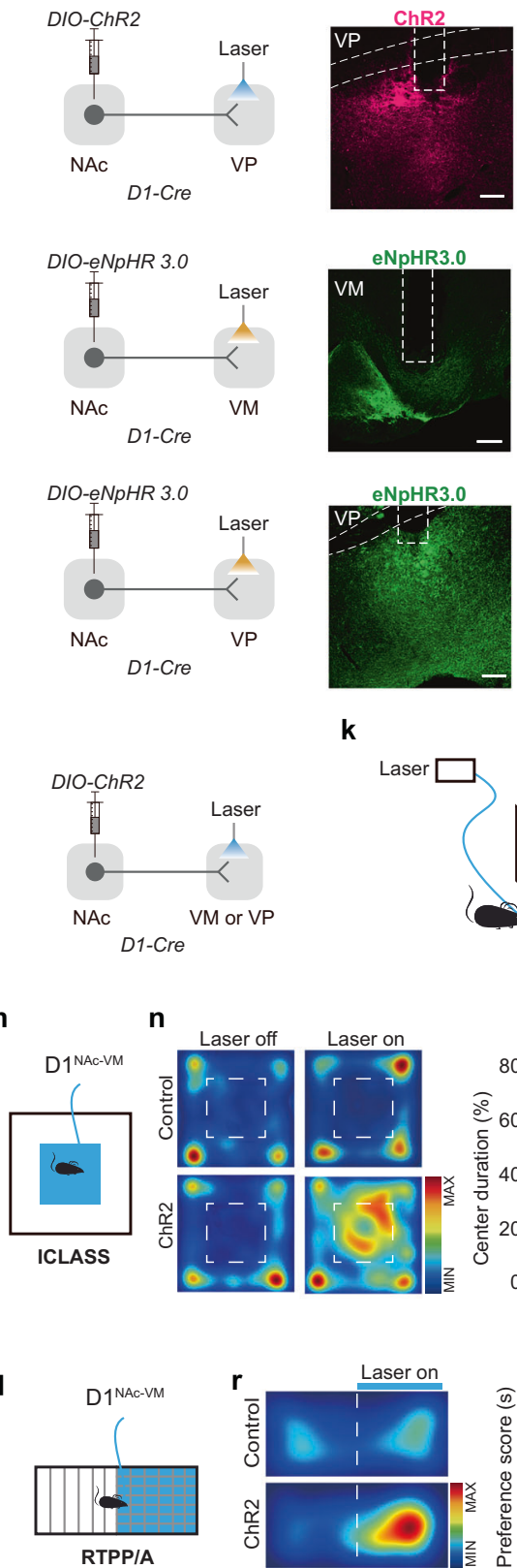

eNpHR3.0

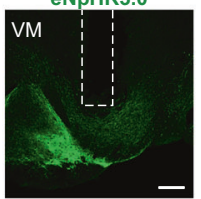

eNpHR3.0

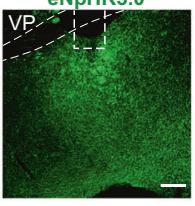

k
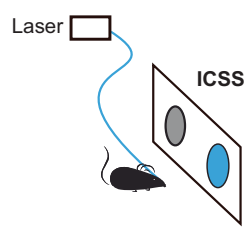
Laser off Laser on
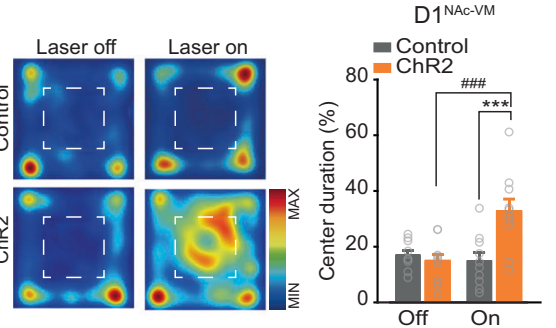

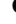
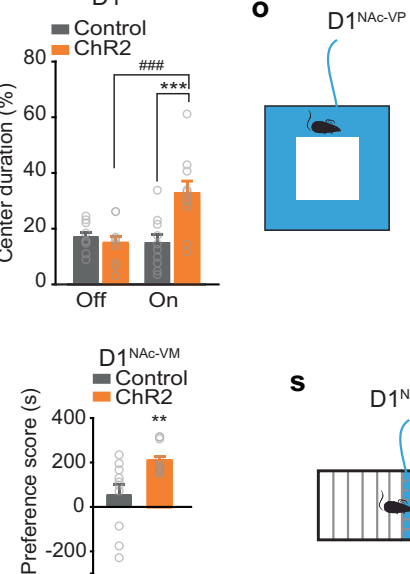
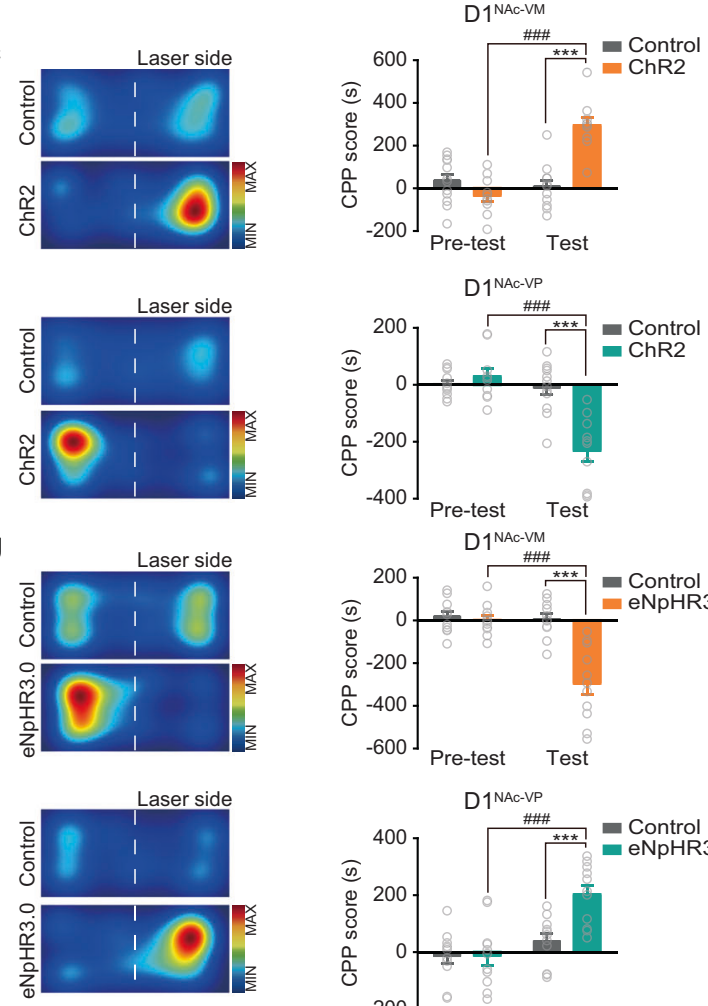

e

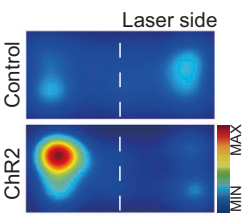

g

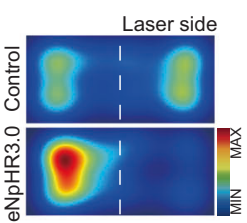

I

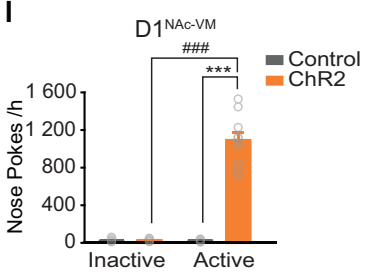

D1 ${ }^{\mathrm{NAc}-\mathrm{VP}}$

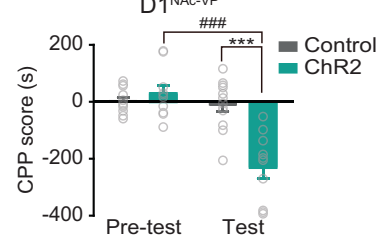

D1 ${ }^{\mathrm{NAC}-\mathrm{VM}}$

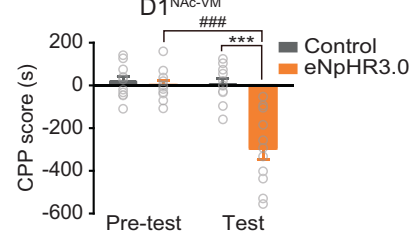

D1 NAc-VP

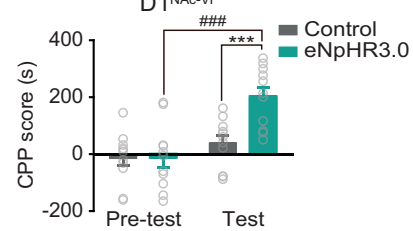

D1 $1^{\mathrm{NAC}-\mathrm{VP}}$

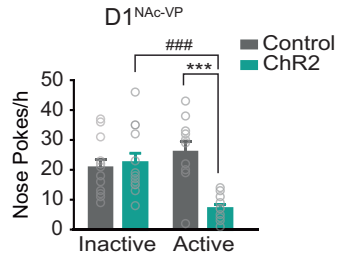

D1 NAc-VP
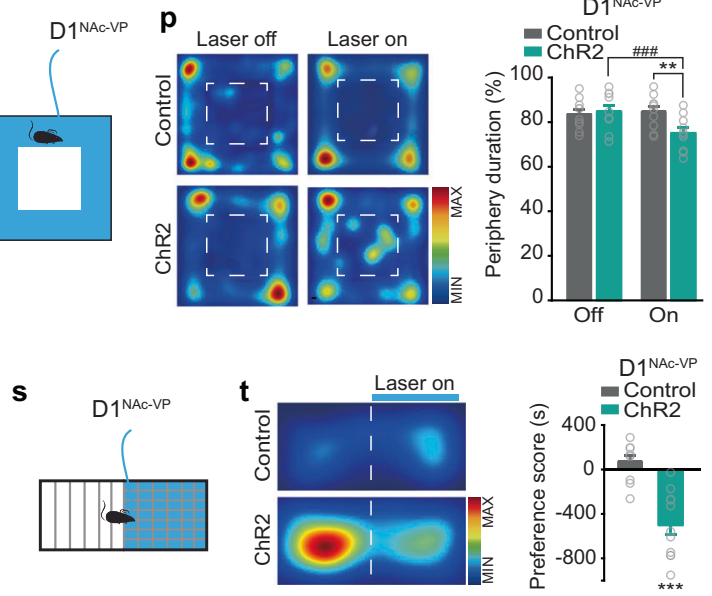

and $52 \%$ of CTB488-labeled cells were D1 ${ }^{\mathrm{NAc}-\mathrm{VP}}$ projectors (Fig. $4 \mathrm{~d}$ ). $6.7 \% \pm 0.4 \%$ of labeled cells contained both CTB488 and CTB647 fluorophores (Supplementary information, Fig. S4a-f). These results were confirmed by retrograde tracing with CTB injected into the VP and VM of D2-eGFP mice (Supplementary information, 
Fig. 2 Activation of $\mathbf{D} 1^{\text {NAc-VP }}$ or $\mathbf{D} 1^{\text {NAc-VM }}$ projections drives opposing emotional responses. a Schematic of CPP/A task. AAV $V_{9} E F 1 a-D / O-$ hChR2-mCherry or AAV -EF1a-DIO-eNpHR3.0-EYFP was injected into the NAc and an optical fiber was implanted over the VM or VP of D1-Cre mice. After three-day laser-paired place conditioning in ChR2 or eNpHR3.0 expressing mice, CPP/A test was performed. $\mathbf{b}$, $\mathbf{d}, \mathbf{f}, \mathbf{h}$ Viral infection and representative images of the optical fiber tip in the VM or VP. c, e, $\mathbf{g}$, $\mathbf{i}$ Representative images of locomotor heat maps of Test and bar graphs of CPP score. [Two-way RM ANOVA: c Control $n=12, \operatorname{ChR} 2 n=10, F_{\text {treatment } \times \text { session }}(1,43)=29.361, P<0.001$; e Control $n=12$, ChR2 $n=$ $10, F_{\text {treatmentxsession }}(1,43)=22.372, P<0.001 ; \mathbf{g}$ Control $n=11$, eNpHR3.0 $n=11, F_{\text {treatmentxsession }}(1,43)=18.787, P<0.001 ; \mathbf{i}$ Control $n=11$, eNpHR3.0 $\left.n=11, F_{\text {treatment } \times \text { session }}(1,43)=7.475, P=0.013\right]{ }^{* *} P<0.001$ vs Control, ${ }^{* \# \# P<0.001 \text { vs Pre-test. } \mathbf{j} \text { Viral infection. AAV }-E F 1 a-D I O-}$ $h C h R 2-m$ Cherry was injected into the NAc and an optical fiber was implanted over the VM or VP of D1-Cre mice. $\mathbf{k}$ Schematic of ICSS task. Mice received optogenetic self-stimulation of $D 1^{\text {NAc-VM }}$ or D1 $1^{\text {NAc-VP }}$ projection in response to nose-poke. I Bar graph of nose-pokes for optical stimulation of $\mathrm{D} 1^{\mathrm{NAc}-\mathrm{VM}}$ or $\mathrm{D} 1^{\mathrm{NAc}-\mathrm{VP}}$ projection. [RM ANOVA with Geisser-Greenhouse correction, D1 ${ }^{\mathrm{NAc}-\mathrm{VM}}$ : Control $n=14, \mathrm{ChR2} n=10$, $F_{\text {virus } \times \text { nosepoke }}(1,22)=215.079, P<0.001$; Two-way RM ANOVA D $1{ }^{\text {NAc-VP. }}$ : Control $n=13$, ChR2 $n=11, F_{\text {virus } \times \text { nosepoke }}(1,47)=29.806, P=$

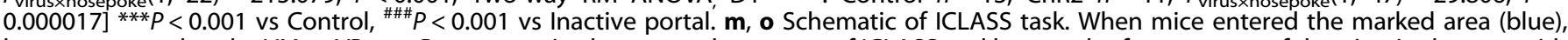
laser was passed to the VM or VP. $\mathbf{n}, \mathbf{p}$ Representative locomotor heat maps of ICLASS and bar graph of percentage of duration in the area with laser stimulation. [Two-way RM ANOVA: $\mathbf{n}$ Control $n=10$, ChR2 $n=10, F_{\text {treatmentxsession }}(1,39)=10.465, P=0.005 ; \mathbf{p}$ Control $n=10$, ChR2 $n=$ $\left.10, F_{\text {treatment } \times \text { session }}(1,39)=9.502, P=0.006\right]{ }^{* *} P<0.01,{ }^{* * *} P<0.001$ vs Control, ${ }^{\# \# \#} P<0.001$ vs Off. $\mathbf{q}$, s Schematic of RTPP/A task. When mice entered the marked chamber (blue), laser was passed to the VM or VP. $\mathbf{r}, \mathbf{t}$ Representative locomotor heat maps of RTPP/A and bar graphs of Preference score. [Two-tailed Student's $t$-test: $\mathbf{r}$ Control $n=10$, ChR2 $n=12 t(20)=-3.127, P=0.005$; Mann-Whitney U test, $\mathbf{t}$ Control $n=10$, ChR2 $n=11, \mathrm{Z}=-3.592, P=0.000068$.] ${ }^{* *} P<0.01$ and ${ }^{* * *} P<0.001$.

Fig. S4g-j). $5.9 \% \pm 0.8 \%$ of labeled cells contained both CTB fluorophores (Supplementary information, Fig. S4i). We also verified the above results with the retrograde AAV strategy. We injected retrograde $A A V$ encoding flp recombinase in the VP and retrograde AAV encoding Cre recombinase in the VM, and a mixture of AAV encoding Cre-dependent tdTomato and flpdependent eGFP in the NAc. ${ }^{27}$ Then we carried out multiplexed single-molecule RNA fluorescence in situ hybridization (smFISH) of drd1 (Supplementary information, Fig. S4k, I). Among $d r d 1^{+}$ neurons, $91.7 \%$ of eGFP $^{+}$cells were $\mathrm{D} 1^{\mathrm{NAc}-\mathrm{VM}}$ projectors and $55.9 \%$ of tdTomato $^{+}$cells were D ${ }^{\text {NAc-VP }}$ projectors. $5.8 \% \pm 1.1 \%$ of labeled cells expressed both tdTomato and eGFP in the NAc (Supplementary information, Fig. S4m-0). Moreover, rabies virusbased monosynaptic tracing ${ }^{28-30}$ revealed that D1 ${ }^{\text {NAC-VP }}$ neurons received more inputs from the BLA and thalamus, and D1 ${ }^{\mathrm{NAc}-\mathrm{VM}}$ neurons received more inputs from the PrL and IL (Supplementary information, Fig. S5a-c).

We next assayed the functional connectivity of D1 $1^{\mathrm{NAc}-\mathrm{VM}}$ and D1 ${ }^{\text {NAc-VP }}$ projectors to the VP by injecting retrograde AAV encoding Cre-dependent flp recombinase in the VP or VM, and AAV encoding flp dependent ChR2 in the NAc of D1-Cre mice.

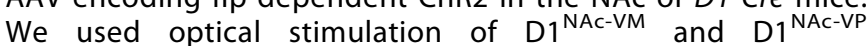
projectors in the VP to evoke GABAergic inhibitory postsynaptic currents (oIPSC) and found that $83.3 \%$ of VP cells received innervation from $\mathrm{D} 1^{\mathrm{NAc}-\mathrm{VP}}$ projectors, while $14.3 \%$ of the VP cells were innervated by D1 ${ }^{\text {NAc-VM }}$ projectors (Fig. 4e, f). The currents were $\mathrm{GABA}_{\mathrm{A}}$ mediated, as they could be blocked by picrotoxin (PTX) (Fig. 4g). These results suggest that the connectivity rate of $\mathrm{D} 1{ }^{\mathrm{NAc}-\mathrm{VP}}$ synapses onto the VP neurons is greater than that of $\mathrm{D} 1^{\mathrm{NAc}-\mathrm{VM}}$ synapses. In addition, chemogenetic or optogenetic activation of $D 1^{\text {NAc-VM }}$ neurons by CNO and laser-induced a preference for CNO- or laser-paired side, while chemogenetic or optogenetic activation of $D 1^{\mathrm{NAc}-\mathrm{VP}}$ neurons induced an avoidance of CNO- or laser-paired side (Supplementary information, Figs. S2c, d and S6). Together, data from these experiments indicate that D1 ${ }^{\text {NAc-VM }}$ and D1 NAcVP projectors are largely two populations within differential neural circuits, providing an anatomical basis for the distinct roles in valence encoding.

We next examined the molecular profiles of $D 1^{\text {NAc-VM }}$ and $D 1^{\text {NAC-VP }}$ populations by retrograde labeling of VM- or VPprojecting NAc neurons with CTB555 and single-cell transcriptome sequencing (Fig. 4h; Supplementary information, Fig. S7a-g). Transcriptome analysis of Drd 1 expressing $\mathrm{CTB} 555^{+}$cells showed that D1 $1^{\mathrm{NAc}-\mathrm{VM}}$ and $\mathrm{D} 1^{\mathrm{NAc}-\mathrm{VP}}$ populations were nicely separated in t-SNE plots (Fig. 4i). We compared differentially expressed genes between the two populations. By assigning a $P$ value $\leq 0.05$ for the level of expression as the cutoff, we detected 779 genes exhibiting enrichment in D1 ${ }^{\text {NAc-VP }}$ population and 132 genes more abundant in D1 $1^{\text {NAc-VM }}$ population (Fig. 4j). Among these genes, the differential expression of Arc and KIf5 in D1 $1^{\mathrm{NAc}-\mathrm{VM}}$ and D1 $1^{\mathrm{NAc}-\mathrm{VP}}$ populations were also verified by smFISH (Supplementary information, Fig. S7h-k). Gene ontology enrichment of D1 ${ }^{\text {NAc-VM }}$ and $D 1^{\text {NAc-VP }}$ populations by gene over representation analysis revealed that $D 1^{\text {NAc-VP }}$ population is distinct from D1 $1^{\text {NAc-VM }}$ population in purinergic receptor signaling and transmembrane transporter activity, while D1 ${ }^{\mathrm{NAc}-\mathrm{VM}}$ populations showed distinct enrichment in pathways such as transcription regulation and nervous system development (Fig. 4k). Notably, the transcript level of Drd1, the gene encoding dopamine D1 receptor, was significantly lower in $\mathrm{D} 1^{\mathrm{NAc}-\mathrm{VP}}$ neurons than $\mathrm{D} 1^{\mathrm{NAc}-\mathrm{VM}}$ neurons (Fig. 4l), and this was confirmed by smFISH of Drd1 combined with AAV-based retrograde labeling $\left(\mathrm{eGFP}^{+}\right.$) as well (Fig. $\left.4 \mathrm{~m}, \mathrm{n}\right)$. Pdyn, Tac1, Chrm4, Foxp1, Is/1, and Slc35d3 are selectively expressed in D1-MSNs, and Adora2a, Sp9, Penk, Gpr52, and Adk are selectively expressed in D2-MSNs. ${ }^{31-33}$ We examined the expression of these D1-MSN and D2-MSN markers in D1 ${ }^{\mathrm{NAc}-\mathrm{VM}}$ and $\mathrm{D} 1^{\mathrm{NAc}-\mathrm{VP}}$ neurons. We found that the percentage of Tac1 and Pdyn positive D1 $1^{\text {NAc-VM }}$ neurons was greater than that of D $1^{\mathrm{NAc}-\mathrm{VP}}$ neurons (Supplementary information, Fig. S8a, c), and the expression levels of Tac1 and $P d y n$ in $D 1^{\text {NAc-VM }}$ neurons were also higher than those in D1 $1^{\text {NAc-VP }}$ neurons (Supplementary information, Fig. S8b).

The molecular features of $\mathrm{D} 1^{\mathrm{NAc}-\mathrm{VM}}$ and $\mathrm{D} 1^{\mathrm{NAc}-\mathrm{VP}}$ neurons, and their distinct anatomic properties may posit their differential intrinsic excitability and synaptic plasticity. By whole-cell patch-clamp recording, we found that the intrinsic excitability of $D 1^{\text {NAc-VP }}$ neurons was greater than that of $D 1^{\text {NAc-VM }}$ neurons but lower than that of D2 $2^{\mathrm{NAc}-\mathrm{VP}}$ neurons (Supplementary information, Fig. S9a-d). The frequency of mIPSC of D1 ${ }^{\text {NAc-VP }}$ neurons was lower than that of $D 1^{\text {NAc-VM }}$ neurons but higher than that of D2 ${ }^{\mathrm{NAc}-\mathrm{VP}}$ neurons (Supplementary information, Fig. S9e-f). The frequency and amplitude of mEPSC were not different among them (Supplementary information, Fig. 9e-f). These results suggest that the basal presynaptic GABA release onto $\mathrm{D} 1^{\mathrm{NAc}-\mathrm{VP}}$ neurons is weaker than that onto $\mathrm{D} 1^{\mathrm{NAc}-\mathrm{VM}}$ neurons, resulting in stronger inhibition of $D 1^{N A c-V M}$ neurons relative to $D 1^{\mathrm{NAc}-\mathrm{VP}}$ neurons.

\section{Activation of $D 1^{\text {NAc-VP }}$ projection inhibits VM DA neurons via VM GABAergic neurons}

With rabies retrograde labeling, we found that the monosynaptic inputs from the NAc onto VP GABAergic neurons were greater than those onto VP glutamatergic neurons (Fig. 5a, b; Supplementary information, Fig. S10a, b). By injection of CTB555 into the 
Conditioned place preference/aversion

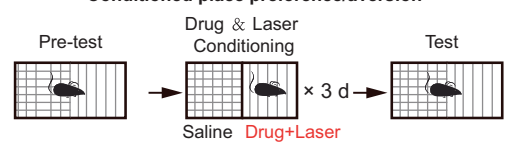

b
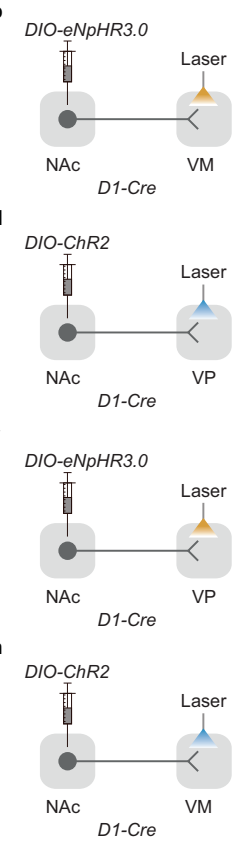

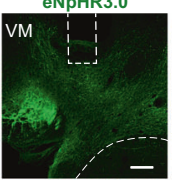

ChR2
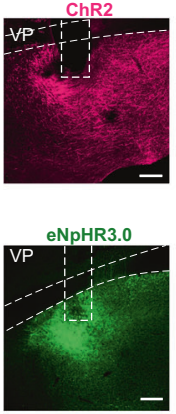

VM

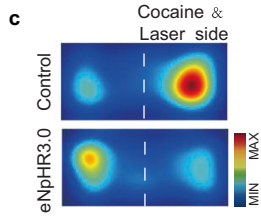

e

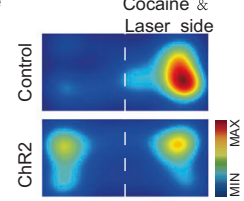

g

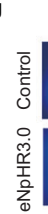

$\mathrm{LiCl} \&$

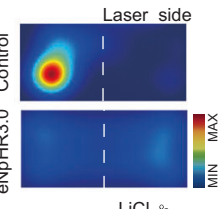

$\mathrm{LiCl} \&$

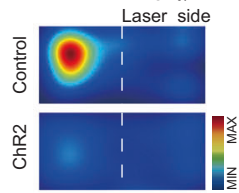

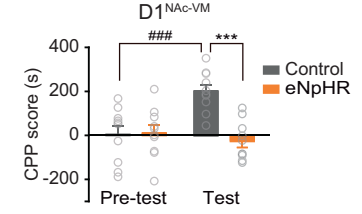
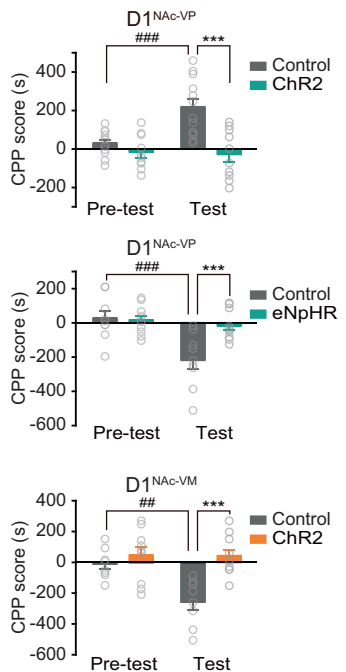

Conditioned place preference
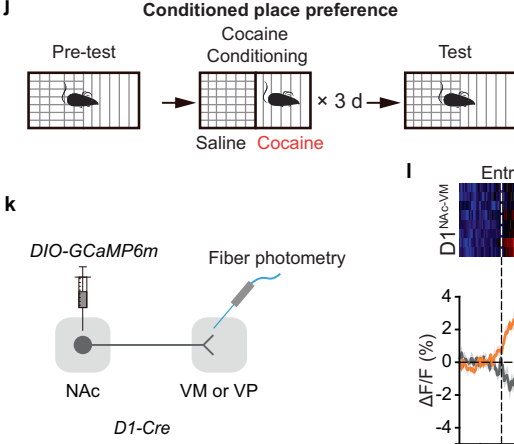

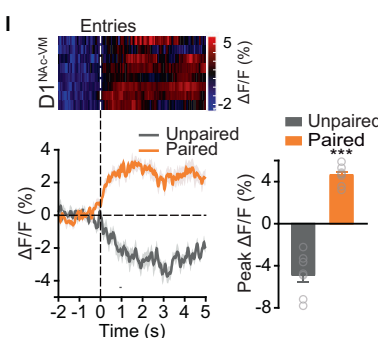

n Conditioned place preference/aversion

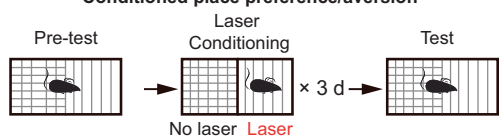

○

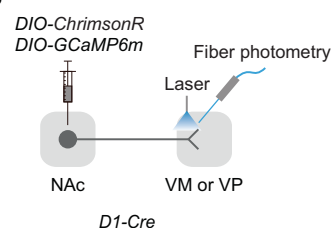

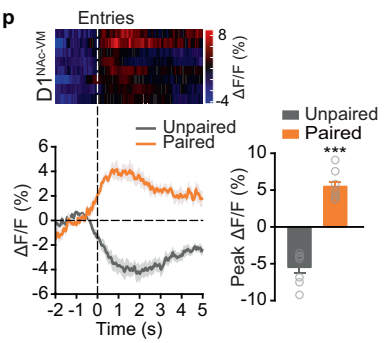

m

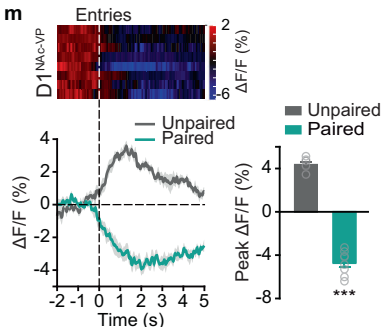

VM and labeling GABA ${ }^{V P}$ or Glu ${ }^{V P}$ neurons with H2B-GFP, we observed that CTB labeled more VM-projecting GABA ${ }^{\mathrm{VP}}$ neurons than VM-projecting Glu ${ }^{\mathrm{VP}}$ neurons (Fig. $5 \mathrm{C}-\mathrm{e}$ ). These data indicate that GABAergic neurons in the VP provide a major input to VM neurons.
The activity of DAergic neurons is regulated by local VM GABAergic neurons. ${ }^{34,35}$ To assess the impact of D1 ${ }^{\text {NAc-VP }}$ and $\mathrm{D} 1^{\mathrm{NAc}-\mathrm{VM}}$ projections onto mesolimbic dopaminergic neurons, we examined the net effect of optical stimulation of these projections on the activity of VM GABAergic and DAergic 
Fig. 3 Activation of D1 $^{\text {NAc-VP }}$ projection inhibits cocaine CPP and activation of D1 ${ }^{\text {NAc-VM }}$ projection inhibits LiCl CPA. a Schematic of experimental design. Laser stimulation was presented during cocaine- or LiCl-place conditioning. After three-day conditioning, the CPP/A test was performed. b, d, f, h Viral infection and representative images. AAV $-E F 1 a-D I O-h C h R 2-m C h e r r y, A A V_{9}-E F 1 a-D I O-m C h e r r y, A A V_{9}-E F 1 a-D I O-$ eNpHR3.0-EYFP, or $A A V_{9}-E F 1 a-D I O-E Y F P$ was injected into the NAc of D1-Cre mice, and optical fibers were bilaterally implanted over the VM or VP. Scale bar: $100 \mu \mathrm{m}$. c, e, g, i Representative images of locomotor heat maps of Test and bar graphs of CPP score. [Two-way RM ANOVA: c Control $n=10$, eNpHR3.0 $n=10, F_{\text {treatment } \times \text { session }}(1,39)=13.823, P=0.002$; e Control $n=12$, ChR2 $n=10, F_{\text {treatment } \times \text { session }}(1,43)=8.751, P=$ 0.008; g Control $n=9$, eNpHR $n=11, F_{\text {treatment } x \text { session }}(1,39)=7.403, P=0.014$; i Control $n=8$, ChR2 $n=10, F_{\text {treatment } \times \text { session }}(1,35)=6.243, P=$ $0.024]{ }^{* *} P<0.01,{ }^{* * *} P<0.001$ vs Control, $\# \# P<0.001$ vs Pre-test. $\mathbf{j}$ Schematic of experimental design. After three-day cocaine-conditioning, photometry recording of $\mathrm{Ca}^{2+}$ transient of $\mathrm{D} 1^{\mathrm{NAc}-\mathrm{VM}}$ and $\mathrm{D} 1^{\mathrm{NAc}-\mathrm{VP}}$ projections during CPP test was performed. $\mathbf{k}$ Viral infection. AAV ${ }_{9}-E F 1 a-D I O-$ GCaMP6m was injected into the NAC of D1-Cre mice, with optical fiber implanted over the VM or VP. I, $\mathbf{m}$ (Top) Representative heat map of Ca ${ }^{2+}$ signaling in $\mathrm{D} 1^{\mathrm{NAc}-\mathrm{VM}}$ and $\mathrm{D} 1^{\mathrm{NAc}-\mathrm{VP}}$ projection during successive entries into cocaine paired side during CPP test. (Bottom) Averaged Ca ${ }^{2+}$ traces and quantification of peak amplitude of $\mathrm{Ca}^{2+}$ events around entry [Two-tailed Student's $t$-test, $\mathrm{D} 1^{\mathrm{NAc}-\mathrm{VM}} n=8, t(14)=-12.858, P<$ $\left.0.001 ; \mathrm{D} 1^{\mathrm{NAC}-\mathrm{VP}} n=8, t(14)=20.054, P<0.001\right]{ }^{* * *} P<0.001$. n Schematic of experimental design. After three-day laser-conditioning, photometry recording of $\mathrm{Ca}^{2+}$ transient of $\mathrm{D} 1^{\mathrm{NAc}-\mathrm{VM}}$ and $\mathrm{D} 1^{\mathrm{NAc}-\mathrm{VP}}$ projections during CPP/A test was performed. $\mathrm{o}$ Viral infection. $A A V_{9}-E F 1 a^{-}$ DIO-GCaMP6m and $A A V_{9}$-hSyn-FLEX-ChrimsonR-tdTomato were injected into the NAc of D1-Cre mice, with optical fiber implanted over the VM or VP. p, q (Top) Representative heat map of $\mathrm{Ca}^{2+}$ signaling in $\mathrm{D} 1^{\mathrm{NAc}-\mathrm{VM}}$ and $\mathrm{D} 1^{\mathrm{NAc}-\mathrm{VP}}$ projections during successive entries into optical stimulation paired side and the opposite side during CPP/A test. (Bottom) Averaged $\mathrm{Ca}^{2+}$ traces and quantification of peak amplitude of $\mathrm{Ca}{ }^{2+}$ events around entry [Two-tailed Student's $t$-test, D1 ${ }^{\mathrm{NAc}-\mathrm{VM}} n=8, t(14)=-10.788, P<0.001 ; \mathrm{D} 1^{\mathrm{NAc}-\mathrm{VP}} n=8, t(14)=-9.615, P<0.001$ ] ${ }^{* * *} P<$ 0.001 .

neurons where NAc and VP projections were both located (Supplementary information, Fig. S10c, d). Selective activation of $\mathrm{GABA}^{\mathrm{NAc}-\mathrm{VM}}$ projection (Chrimson $\mathrm{R}^{+}$) induced a decrease, while activation of GABA ${ }^{\mathrm{NAc}-\mathrm{VP}}$ projection $\left(\mathrm{ChR2} 2^{+}\right)$induced an increase in the GCaMP fluorescence in VM GABAergic neurons (Fig. 5f, g). Activation of $\mathrm{D} 1^{\mathrm{NAc}-\mathrm{VM}}$ projection $\left(\right.$ Chrimson $\mathrm{R}^{+}$) induced an increase, while activation of $\mathrm{D} 1{ }^{\mathrm{NAc}-\mathrm{VP}}$ projection $\left(\mathrm{ChR} 2^{+}\right)$elicited a decrease in GCaMP fluorescence in VM DAergic neurons (Fig. 5h, i). Similar to the stimulation of $\mathrm{D} 1^{\mathrm{NAc}-\mathrm{VP}}$ projection, activation of $\mathrm{D} 2{ }^{\mathrm{NAc}-\mathrm{VP}}$ projection $\left(\mathrm{ChR2} 2^{+}\right)$resulted in a decrease in GCaMP fluorescence in VM DAergic neurons (Fig. 5j). These data suggest that activation of D1 ${ }^{\text {NAC-VM }}$ projection inhibits VM GABAergic neurons and in turn activates VM DAergic neurons, while activation of NAc-VP projection, including the projections from both D1- and D2-MSN, increases the activity of VM GABAergic neurons and thus decreases the activity of VM DAergic neurons.

The NAc receives DAergic projection from the VM. To directly probe DA release in the NAc, we recorded fluorescence dynamics of DA2m, ${ }^{36,37}$ a newly developed DA sensor, in the NAC upon reward and aversive stimuli (Fig. 6a). When mice voluntarily licked sucrose $(5 \%)$, ate palatable food, or retreated from the novel object in the approach-avoidance task, we observed a concordant increase of DA sensor fluorescence (Fig. 6b-d). In contrast, air puff and tail suspension both reduced basal DA sensor fluorescence (Fig. 6e, f), reflecting bidirectional changes of local DA release in response to reward and aversion. Next, we monitored DA release

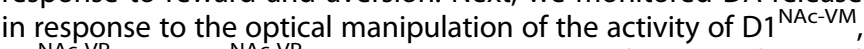
$\mathrm{D} 1^{\mathrm{NAc}-\mathrm{VP}}$, or D2 ${ }^{\mathrm{NAc}-\mathrm{VP}}$ projections (Fig. $6 \mathrm{~g}-\mathrm{k}$ ). We detected enhanced DA level in response to optical activation of D1 ${ }^{\mathrm{NAc}-\mathrm{VM}}$ projection (Fig. 6i), and a reduction in response to optical activation of $\mathrm{D} 1^{\mathrm{NAc}-\mathrm{VP}}$ and $\mathrm{D} 2^{\mathrm{NAc}-\mathrm{VP}}$ projection (Fig. $6 \mathrm{j}, \mathrm{k}$ ). The results above indicate that activation of $D 1^{\mathrm{NAc}-V M}$ projection promotes DA release and activation of $\mathrm{D} 1^{\mathrm{NAc}-\mathrm{VP}}$ projection reduces DA release into the NAc, suggesting that these two subpopulations of D1-MSNs work cooperatively to control the balance of dopamine and reward-aversion states.

\section{DISCUSSION}

In this study, we find that $\mathrm{D} 1^{\mathrm{NAc}-\mathrm{VM}}$ and $\mathrm{D} 1^{\mathrm{NAc}-\mathrm{VP}}$ neurons are two largely separate populations of D1-MSNs with distinct molecular profiling, specific neural circuits, and membrane excitability. Activation of $\mathrm{D} 1^{\mathrm{NAc}-\mathrm{VM}}$ projection increases dopamine release into $\mathrm{NAC}$ and promotes reward, whereas activation of $\mathrm{D} 1^{\mathrm{NAc}-\mathrm{VP}}$ projection reduces dopamine level and elicits aversion. Activation of D1 ${ }^{\mathrm{NAc}-\mathrm{VM}}$ and D $1^{\mathrm{NAc}-\mathrm{VP}}$ projections drives opposing regulation of VM DAergic neurons and promotes opposite internal emotional states. Thus, we believe that D1-MSNs composed of different subpopulations within the NAc stringently control DA balance and responses to environmental stimuli.

As illustrated in Fig. 6l, we propose an updated working model of the regulation of mesolimbic D1-MSN circuits on dopamine release. D1 ${ }^{\mathrm{NAc}-\mathrm{VM}}$ neurons, which express higher levels of D1 receptor, predominantly project to the VM and inhibit VM GABAergic neurons, disinhibiting DAergic neurons projecting back to the NAC and promoting dopamine release into the NAC. The functions of $D 1^{\text {NAc-VM }}$ neurons are consistent with the conventional role of D1-MSNs. Conversely, D1 ${ }^{\text {NAc-VP }}$ neurons, which have lower levels of D1 receptor and predominantly target the VP to inhibit VP GABAergic neurons, ultimately disinhibit VM GABAergic neurons and thus inhibit the activity of VM DAergic neurons, hindering DA release into the NAc. Thus, the effects of activation of $\mathrm{D} 1^{\mathrm{NAC}-\mathrm{VP}}$ and $\mathrm{D} 1^{\mathrm{NAc}-\mathrm{VM}}$ pathways on dopamine release and emotional valence are opposing to each other. Moreover, activation of D1 ${ }^{\mathrm{NAc}-\mathrm{VM}}$ neurons increases DA release and triggers the activation of $D 1^{\mathrm{NAc}-\mathrm{VP}}$, which inhibits DAergic neurons in the VM to reduce DA level in the NAc through net disinhibition of VM GABAergic neurons. This regulation of DA level in the NAc by D1 ${ }^{N A c-V P}$ may occur when the DA level is higher than normal, since D1 ${ }^{\text {NAc-VP }}$ neurons possess fewer D1 receptors than $D 1^{N A c-V M}$ neurons. VM GABAergic neurons receive direct inhibition from $D 1^{\text {NAc-VM }}$ neurons and indirect disinhibition from D1 $1^{\text {NAc-VP }}$ neurons. These two neuronal populations cooperatively regulate the balance of NAc dopamine level and encode emotional valence through VM GABAergic neurons (Fig. 6l).

\section{$D 1^{\text {NAc-VM }}$ and D1 ${ }^{\text {NAc-VP }}$ neuronal populations encode opposite valences}

The prevailing hypothesis posits that D1-MSNs and D2-MSNs encode opposing valences. Activation of D1-MSNs induces reward and positive reinforcement, whereas activation of D2-MSNs produces aversion and negative reinforcement. However, some studies provide apparent contradictory results. Optical activation of D1-MSNs induces place reward or avoidance depending on their neuronal stimulation pattern, ${ }^{38}$ and optical stimulation of dynorphin-positive cells, which co-express D1 receptor, in dorsal and ventral NAC shell drives real-time place preference and avoidance respectively. ${ }^{39}$ A recent paper reported that VTA projecting D1-MSNs in the NAc medial and lateral shell have distinct effects on behavior. Specifically, the lateral projections to VTA produce place preference and ICSS, but the medial projections to VTA mostly suppress behavioral responding. ${ }^{40}$ Studies also show that both D1- and D2-MSNs are activated by aversive stimuli such as food restriction ${ }^{41}$ or footshock. ${ }^{42}$ In addition, one recent work shows that optogenetic activation of D2-MSNs in the dorsomedial NAcSh 
tdT CTB488 CTB647
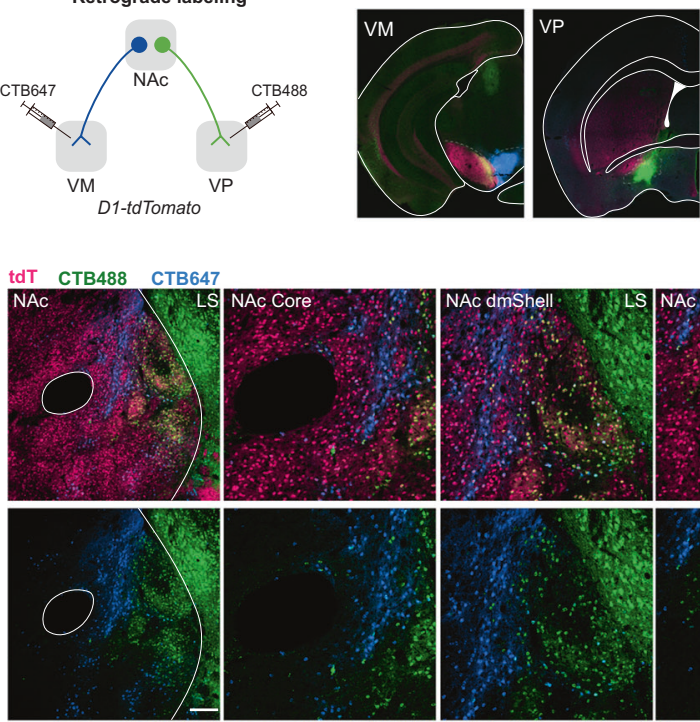

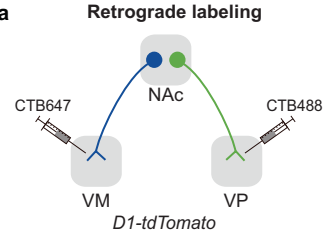

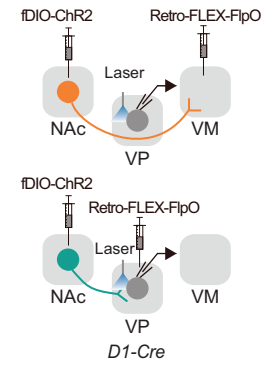
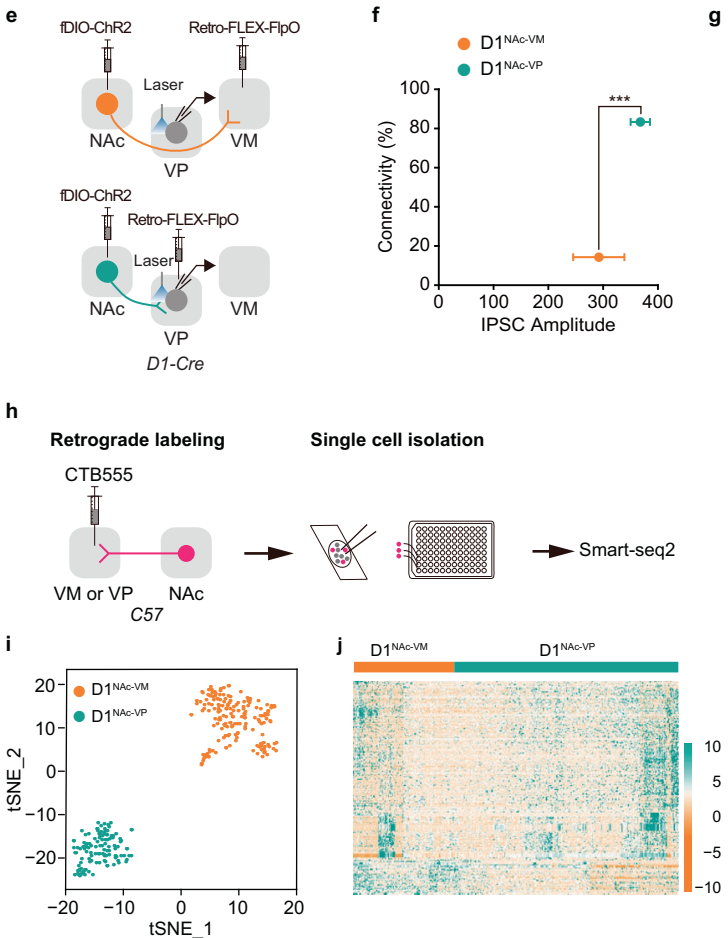

g
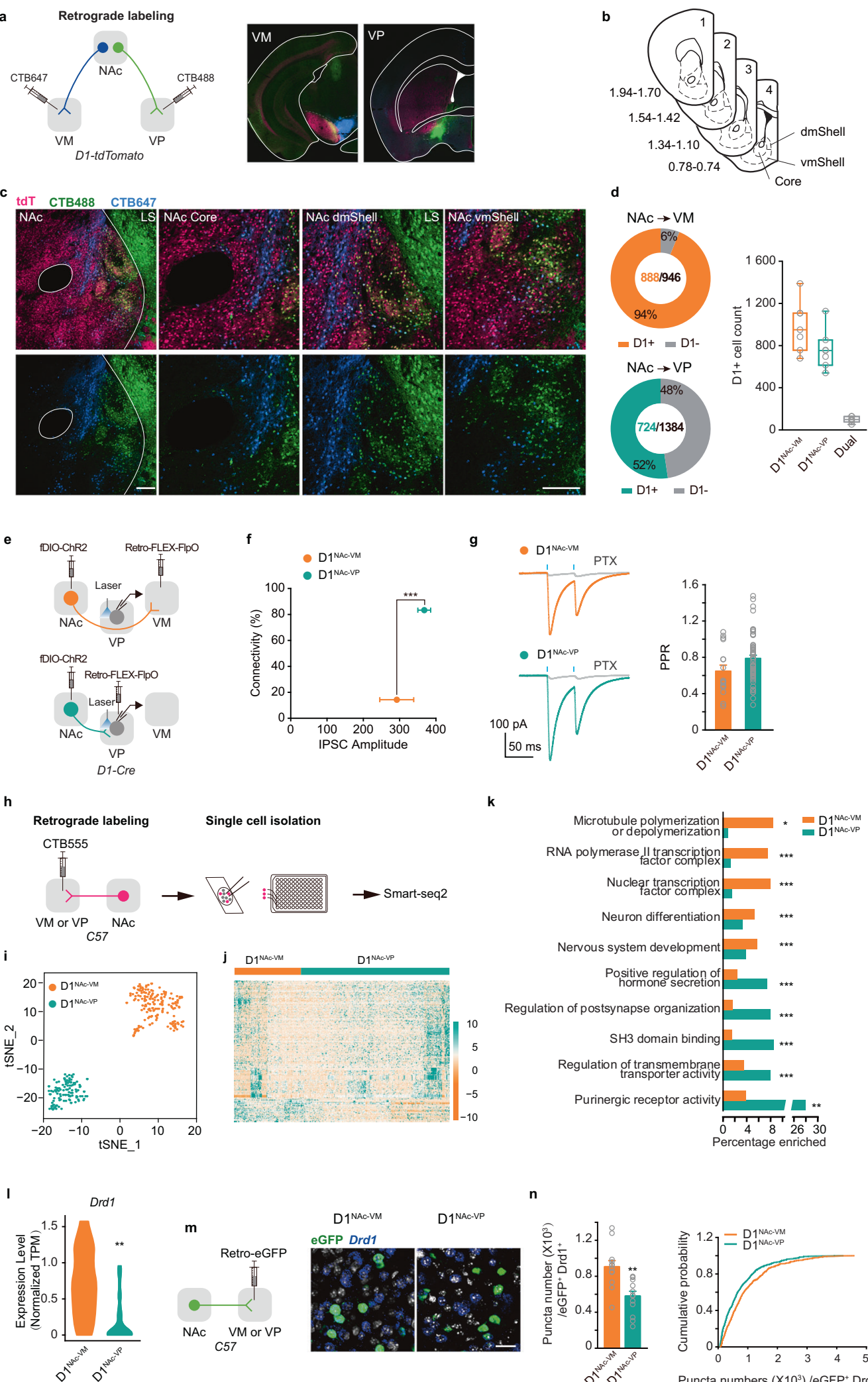

m
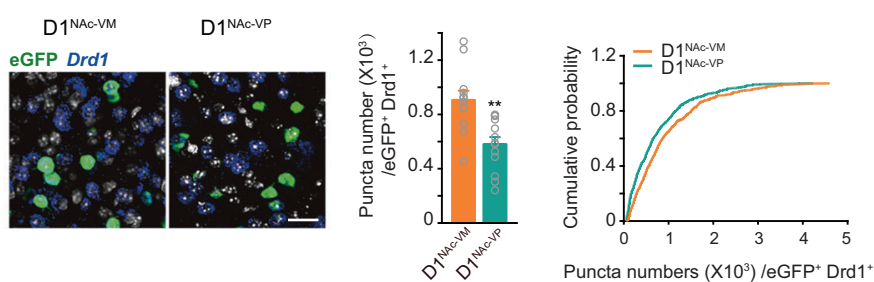

drives preference for stimulation side, whereas activation of ventral NAcSh D2-MSNs induces avoidance for stimulation side. ${ }^{43}$ These data suggest the diversity in valence encoding of MSNs in the NAc. In this study, we find that D1 ${ }^{\text {NAc-VM }}$ neurons show properties that resemble those of the conventional D1-MSNs, ${ }^{44}$ promoting reward and positive reinforcement learning. By contrast, D1 ${ }^{\text {NAc-VP }}$ neurons function opposite to the conventional D1-MSNs, eliciting aversion and negative reinforcement learning. These intermingled D1 $1^{\mathrm{NA}-\mathrm{VM}}$ and $\mathrm{D} 1^{\mathrm{NAc}-\mathrm{VP}}$ neurons in the NAc showing functional diversity and opponency in valence production might attribute to the 
Fig. $4 \mathrm{D}^{\mathrm{NAc}-\mathrm{VM}}$ and $\mathrm{D} 1^{\mathrm{NAc}-\mathrm{VP}}$ neurons are two populations with distinct anatomic, molecular, and electrophysiological features. a Schematic of CTB labeling and confocal images for injections of CTB647 into the VM and CTB488 into the VP of D1-tdTomato mice. b Schemtic of sites imaged for quantification across the rostro-caudal gradient of NAc. c Confocal images for CTB labeled neurons in the NAC core, dmShell, and vmShell. Scale bar: $100 \mu \mathrm{m}$. d Left: quantification of CTB and tdTomato (D1-MSNs) overlap in the NAc. Right: summary of the number of CTB647 ${ }^{+}$D1-MSNs, CTB488 ${ }^{+}$D1-MSNs and double positive D1-MSN in the NAc [CTB647: $888 \pm 89$ cells, CTB488:724 \pm 81 cells of

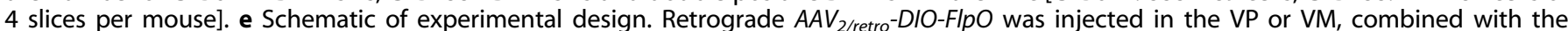
injection of AAV9-EF1a-fDIO-ChR2-mCherry into the NAc of D1-Cre mice. f Connectivity plot summarizing optogenetic circuit mapping. In the VP, $83.3 \%$ of neurons were innervated by D1 ${ }^{\text {NAc-VP }}$ neurons ( 66 cells from 6 mice; average connectivity strength: $367.77 \pm 17.66 \mathrm{pA}$ ), whereas only $14.3 \%$ VP neurons received innervation from D1 NAc-VM neurons (112 cells from 8 mice; average connectivity strength: $292.13 \pm 46.74$ $\mathrm{pA})$. Connectivity rate, Pearson $\chi 2$ ratio, 26.670, $P<0.001$. g Representative responses to optogenetic stimulation (blue bars) of D1 ${ }^{\mathrm{NAc}-\overline{\mathrm{V}} \mathrm{M}}$ and D1 $1^{\text {NAc-VP }}$ projections in the VP. Currents were blocked by picrotoxin (PTX: $20 \mathrm{mM}$ ) [D1 $1^{\text {NAc-VM }}, 0.65 \pm 0.07 ; \mathrm{D} 1^{\mathrm{NAc}-\mathrm{VP}}, 0.79 \pm 0.04 ; t(69)=-1.852$, $P=0.0683$ ]. $h$ Workflow for single cell sequencing of $D 1^{N A c-V M}$ and $D 1^{N A c-V P}$ neurons retrogradelly labeled by CTB. i Unbiased clustering of D1expressing neurons using t-SNE according to their whole-transcriptome correlation distance. Each cell is represented as a dot and colored by a clustering algorithm. $\mathbf{j}$ Heatmap of the differentially expressed genes between the two populations. Each column represents a single cell, and each row represents a single gene. The genes are ordered by hierarchical clustering the expression difference. Color represents the expression $Z$-score of the cells. $\mathbf{k}$ Gene ontology overrepresentation analysis of $D 1^{N A c-V M}$ and $D 1^{N A c-V P}$ populations. Bar length represents the number of genes differentially expressed in the population/the number of genes that are expressed and annotated to the pathway [Fisher's exact test, see Supplementary information, Table S1]. ${ }^{*} P<0.05,{ }^{* *} P<0.01,{ }^{* * *} P<0.001$. I Bar graph showing the expression of Drd1 in D1 ${ }^{\mathrm{NAc}-\mathrm{VM}}$ and $\mathrm{D} 1^{\mathrm{NAc}-\mathrm{VP}}$ neurons [Negative binomial generalized linear models, D1 ${ }^{\mathrm{NAc}-\mathrm{VM}} n=120$ cells, D1 $^{\mathrm{NAc}-\mathrm{VP}} n=182$ cells, W $=2.607, P=0.009$.] ${ }^{* *} P<0.01$. $\mathbf{m}$ Viral infection and representative confocal images of eGFP and Drd1 expression in the NAc. C57 mice were injected with $A A V_{2 / \text { retro }}-h S_{5 y}-$ eGFP into the VP or VM. Then smFISH was performed with Drd1 in the brain slice containing the NAc. Scale bar: $25 \mu \mathrm{m}$. $\mathbf{n}$ Quantification bar graph and cumulative frequency distribution of Drd1 expression in D1 $1^{\mathrm{NAc}-\mathrm{VM}}$ and D1 ${ }^{\mathrm{NAc}-\mathrm{VP}}$ neurons (Drd1 ${ }^{+}$eGFP ${ }^{+}$). [Two-tailed Student's $t$-test, $t(23)=3.757, P=0.001$; Kolmogorov-Smirnov test, $P<0.001$.] ${ }^{* *} P<0.01,{ }^{* * *} P<0.001$.

dichotomous results. Additionally, the opposing responses of $\mathrm{D} 1^{\mathrm{NAc}-}$ $\mathrm{VM}$ and $\mathrm{D} 1^{\mathrm{NAc}-\mathrm{VP}}$ neurons to environmental stimuli might synergistically determine the valence state. The roles of heterogeneous NAc D1-MSNs in valence encoding deserve extensive study.

\section{D1 ${ }^{\text {NAc-VP }}$ projection negatively regulates mesolimbic DA}

\section{system}

Previous studies suggest that the VP function is a major mechanism for reward in the brain. $G_{A B A}$ receptor agonist muscimol injection in the VP attenuates saccharine flavored water intake and $\mathrm{GABA}_{\mathrm{A}}$ receptor antagonist bicuculline increases eating behavior and food intake. ${ }^{45,46}$ The repeatedly pressing the level for electrical stimulation of the VP indicates that activation of the VP is sufficient to induce a reward. ${ }^{47}$ VP contains two major projection neuron types, including GABAergic neurons (GABA ${ }^{\mathrm{VP}}, 73 \%$ of all VP neurons) and glutamatergic (Glu ${ }^{\mathrm{VP}}, 23 \%$ of all VP neurons) neurons. Activation of GABA $\mathrm{VP}$ neurons facilitates cocaine seeking during withdrawal of cocaine self-administration mice, but activation of $\mathrm{Glu}^{\mathrm{VP}}$ neurons suppresses this effect. ${ }^{48}$ Activation of GABA ${ }^{\mathrm{VP}}$ neurons drives place preference through the projection to the VM, while activation of Glu ${ }^{\mathrm{VP}}$ neurons induces place avoidance through the projection to the lateral habenula. ${ }^{49}$ These studies suggest that activation of GABA $\mathrm{VP}$ and Glu $\mathrm{VP}$ neurons produces reward and aversion, respectively, through different downstream circuits. Moreover, the reward induced by activation of the VP should primarily be ascribed to activation of GABA ${ }^{\mathrm{VP}}$ neurons, since Glu $\mathrm{VP}$ neurons might function opposingly to $\mathrm{GABA}^{\mathrm{VP}}$ neurons. Our retrograde tracing data show that the $N A C$ sends more inputs onto GABA ${ }^{\mathrm{VP}}$ neurons than Glu ${ }^{\mathrm{VP}}$ neurons, and GABA ${ }^{\mathrm{VP}}$ neurons send more projections to VM neurons than Glu ${ }^{V P}$ neurons do. Our photometry recording data reveal a negative regulation within the mesolimbic system that activation of NAc-VP projection (including $\mathrm{D} 1^{\mathrm{NAC}-\mathrm{VP}}$ and D2 ${ }^{\mathrm{NAc}-\mathrm{VP}}$ ) increases the activity of VM GABAergic neurons, then decreases the activity of VM DAergic neurons, and suppresses DA release in the NAc. Combined with our electrophysiological recording data and results from other groups that D1- and D2-MSNs from the NAc equally innervate the VP through the inhibitory projections, ${ }^{10,50}$ we speculate that the net effect of the inhibition of VM DAergic neurons and DA release in the NAC produced by stimulation of GABAergic $D 1^{\text {NAc-VP }}$ projection may primarily be ascribed to its inhibition onto GABA ${ }^{V P}$ neurons that disinhibit GABAergic neurons in the VM and finally suppress the activity of VM DAergic neurons. In addition, optical activation of $D 1^{\text {NAc-VP }}$ projection-induced negative valence could also be mediated by the GABAergic inactivation of the VP as suggested by studies mentioned above, and the data of inhibition of VM DAergic neurons obtained in this study.

It is speculated that activation of accumbal D1R by dopamine enhances excitability of D1-MSNs and activation of D2R decreases excitability of D2-MSNs, which may synergistically augment DA release, producing maximal rewarding effects. However, the suppression mechanism and the brake on DA release in the NAC are unclear. Our results of in vivo fiber photometry recording and behavioral tests indicate activation of $D 1^{\text {NAc-VP }}$ projection inhibits VM DAergic neurons, decreases DA level in the NAC, and induces aversion, opposite to the outcome of activation of $\mathrm{D} 1^{\mathrm{NAc}-\mathrm{VM}}$ projection. The classical model points out that D1-MSNs in the NAC activate DAergic neurons through their inhibition of local VTA GABAergic neurons. ${ }^{34,35}$ Thus, our study provides the novel evidence that D1-MSNs can down-regulate DA release through the VP circuit. Fast increase of DA concentration resulting from phasic bursts in DA neurons may activate $D 1^{\text {NAc-VP }}$ neurons and further DA release is in turn suppressed through this negative regulation loop. Therefore, $D 1^{\mathrm{NAC}-\mathrm{VP}}$ MSN-mediated negative regulation of dopamine level is critical for dopamine homeostasis and reward-aversion state.

Cocaine, a psychoactive drug, attaches to the dopamine transporter and blocks the normal recycling process, resulting in a buildup of dopamine in the synapse. Our data show that the reward effects of cocaine might be canceled out by activation of D1 ${ }^{\text {NAc-VP }}$ pathway that inhibits DA release in the NAc and results in an aversive state. Lithium, an antibipolar drug, is commonly used in the management of mood disorders along with drugs targeting central monoaminergic transmission. ${ }^{51}$ Studies show that administration of lithium salts inhibits locomotion induced by novel environment, ${ }^{52}$ suppresses DA-associated behaviors in experimental animal models, ${ }^{53}$ and decreases DA release. ${ }^{54} \mathrm{LiCl}$ conditioning results in place avoidance ${ }^{55}$ and taste aversion. ${ }^{56}$ Although the effects of lithium on DA system are still unclear, our data reveal that the aversive effects of lithium might be mediated by either inhibition of $D 1^{\text {NAc-VM }}$ pathway or activation of $D 1^{\text {NAc-VP }}$ pathway through the suppression of DA release in the NAc. These data support that D1 $1^{\text {NAc-VM }}$ and $\mathrm{D} 1^{\mathrm{NAc}-\mathrm{VP}}$ pathways cooperatively regulate DA release into NAc and drive opposing emotional valence.

Accumbal D1 ${ }^{\text {NAc-VP }}$ and D1 ${ }^{\text {NAc-VM }}$ MSNs possess dichotomous anatomical, electrophysiological, and molecular properties In this study, we find that VP-projecting and VM-projecting D1-MSNs are largely two distinct populations, in contrast to the 


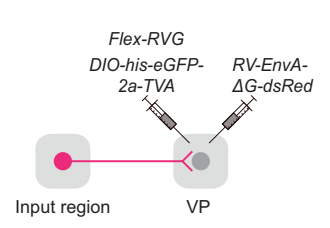

Gad-Cre or vGlut2-Cre

C

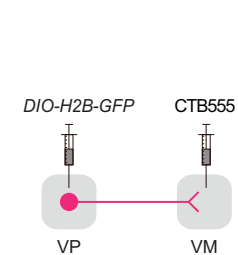

Gad-Cre or VGlut2-Cre
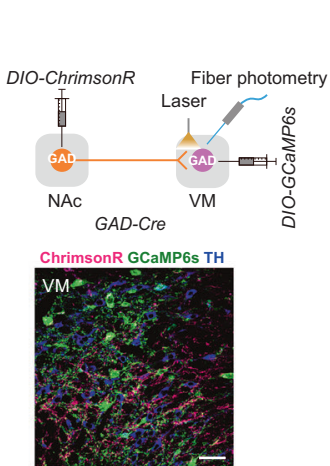

h
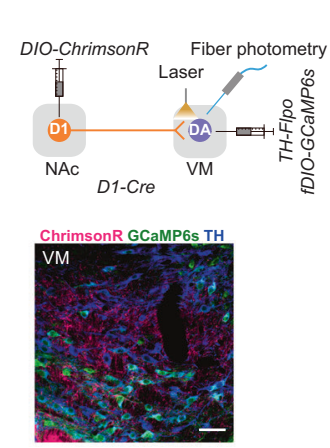

j

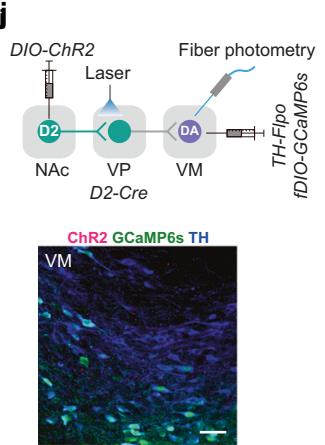

b

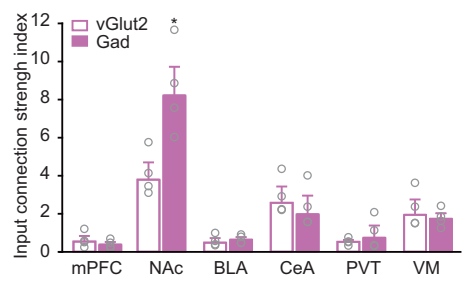

d

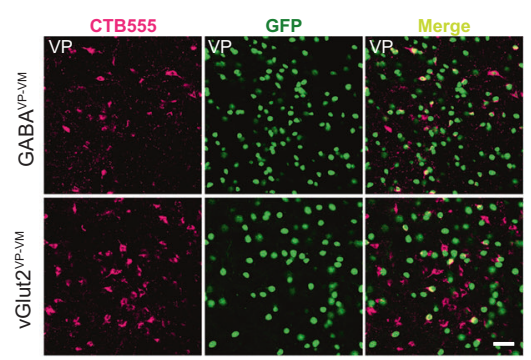

e

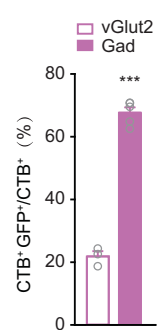

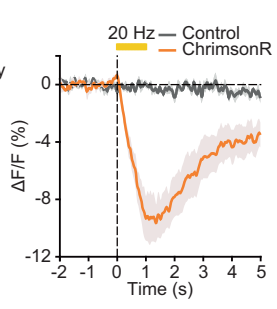

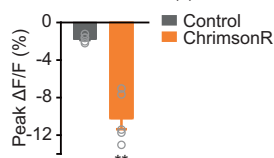

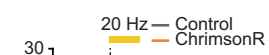

g

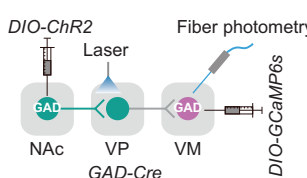

ChR2 GCaMP6s TH
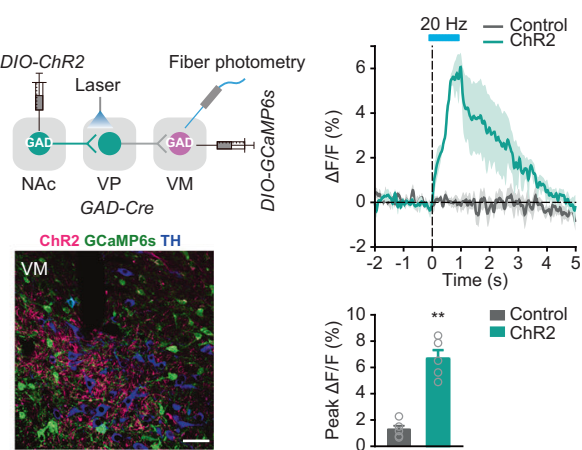

i
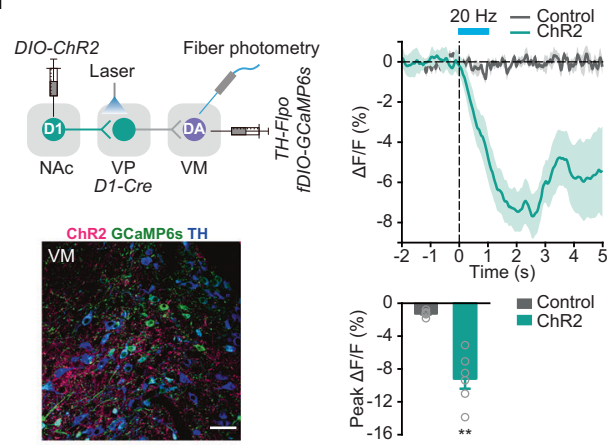

previous study that accumbens D1-MSNs largely collateralize to both the VP and VM. ${ }^{57}$ The reason for this discrepancy might be due to different strategies of retrograde labeling. Our results are consistent with one recent report suggesting that D1-MSNs in the NAc medial shell projecting to VM and VP are largely distinct populations that constitute multiple parallel output pathways with different circuit connectivity and cocaine induced synaptic plasticity. $^{58}$

Several studies show that stimuli of positive and negative valence could both induce dopamine release in the NAc from the 
Fig. $5 \mathrm{D} 1^{\text {NAc-VM }}$ and D1 ${ }^{\text {NAc-VP }}$ pathways drive opposing regulation of VM DAergic and GABAergic neurons. a, b Schematic of rabies virusbased monosynaptic tracing (a) and quantification of input connection strength index (b). RV-ENVA-deltaG-dsRed (RVdG) was injected into the VP 2-week after unilateral injection of $A A V_{9}-E F 1 a-D I O-h i s-e G F P-2 a-T V A$, and AAV 9 -EF1a-DIO-RVG into the VP of Gad-Cre and vGlut2-Cre mice. Numbers of labeled presynaptic neurons/numbers of starter neurons were plotted [Two-tailed Student's $t$-test, Gad $n=4$, vGlut2 $n=4$, NAc $t(6)=3.318, P=0.016]{ }^{*} P<0.05$. c-e CTB retrograde labeling of GABA ${ }^{\mathrm{VP}-\mathrm{VM}}$ and vGlut2 ${ }^{\mathrm{VP}-\mathrm{VM}}$ neurons. CTB555 was injected into the VM and $A A V_{9}-E F 1 a-D I O-H 2 B-G F P$ was injected into the VP of Gad-Cre or vGlut2-Cre mice (c). Representative images of retrograde labeling (d). Percentage of GABA ${ }^{\mathrm{VP}-\mathrm{VM}}$ and vGlut2 ${ }^{\mathrm{VP}-\mathrm{VM}}$ neurons (e) [Two-tailed Student's $t$-test, Gad $n=5$, vGlut2 $n=3, t(6)=-17.902, P=0.000002$.] ${ }^{* * *} P<0.001$. f-j Optical fibers were implanted in the VM/VP and VM to exert laser stimulation and record CaMP6s signal simultaneously. Confocal images show ChrimsonR ${ }^{+}$or $\mathrm{ChR2}^{+}$terminals (Red), GCaMP6s ${ }^{+}$cell bodies (Green), and $\mathrm{TH}^{+}$neurons (Blue) in the VM. Scale bar: $50 \mu \mathrm{m}$. Statistical graph of group average GCaMP responses aligned to the onset of optical stimulation and bar graph of peak response to optical stimulation at $20 \mathrm{~Hz}$. AAV $V_{9}$-hSyn-FLEX-ChrimsonR-tdTomato or $A A V_{9}-E F 1 a-D I O-h C h R 2-m C h e r r y$ was injected into the NAC and AAV $-E F 1 a-D I O-G C a M P 6 s$ was infected in the VM of Gad-Cre mice. Calcium activity of VM GABAergic neurons in response to optical stimulation of GABA ${ }^{\text {NAc-VM }}$ or GABA ${ }^{\text {NAc-VP }}$ projection was recorded $(\mathbf{f}, \mathbf{g})$. [f Control $n=5$, ChrimsonR $n=5$, Two-tailed Student's $t$-test, $t(8)=7.014, P=0.000111 ; \mathbf{g}$ Control $n=5$, ChR2 $n$ $=5$, Mann-Whitney $U$ test, $Z=2.611, P=0.0079]{ }^{* *} P<0.01$ and ${ }^{* * *} P<0.001$. AAV ${ }_{9}$-hSyn-FLEX-ChrimsonR-tdTomato or AAV $-E F 1 a-D I O-h C h R 2-$ $m$ Cherry was infected into the NAC and $A A V_{9}-T H-F I p O$ and $A A V_{9}-E F 1 a-f D I O-G C a M P 6 s$ were injected into the VM of D1-Cre mice. Activity of VM DAergic neurons in response to optical stimulation of $\mathrm{D} 1^{\mathrm{NAc}-\mathrm{VM}}$ or $\mathrm{D} 1^{\mathrm{NAc}-\mathrm{VP}}$ projection was recorded $(\mathbf{h}, \mathbf{i})$. [Mann-Whitney $\mathrm{U}$ test: $\mathbf{h}$ Control $n=$ 6, ChrimsonR $n=6, Z=2.882, P=0.0022$; i Control $n=6$, ChR2 $n=6, Z=-2.882, P=0.0022] * * P<0.01$. (j) AAV ${ }_{9}-E F 1 a-D I O-h C h R 2-m C h e r r y$ was injected into the NAC and $A A V_{9}-T H-F l p O$ and $A A V_{9}-E F 1 a-f D I O-G C a M P 6 s$ were injected into the VM of D2-Cre mice. Activity of VM DAergic neurons in response to optical stimulation of $\mathrm{D} 2{ }^{\mathrm{NAc}-\mathrm{VP}}$ projection was recorded. [Mann-Whitney $\mathrm{U}$ test, Control $n=6, \mathrm{ChR2} n=6, \mathrm{Z}=-2.882$, $P=0.0022] * * P<0.01$.

VM. Nature reward, such as sucrose consumption, evokes robust increase of fluorescence of DA sensor in both NAc core and shell, while aversive stimuli, such as unpredictable footshock and tail pinch, suppress fluorescence of DA sensor in the NAc core and the dmshell, but increase DA signal in the vmshell. ${ }^{59,60} \mathrm{~A}$ recent study using fibre photometry shows that footshock decreases the calcium fluorescence in VTA-NAc core and VTA-NAc dmshell DAergic projection, but increases the calcium fluorescence in VTANAc vmshell DAergic projections, while sucrose licking increases the calcium fluorescence in VTA-NAc shell DAergic projection. ${ }^{28}$ These studies suggest that positive stimuli increase DA release in the NAc core and shell, while negative stimuli decrease DA release in NAc core and dmshell, but increase DA release in the NAC vmshell. In this study, we implanted the fiber $(400 \mu \mathrm{m})$ above the NAc core and dmshell, where DA release was recorded. Consistent with these studies, we find that positive stimuli increase, and negative stimuli decrease DA release in the NAc core and dmshell. VM dopamine neurons are heterogeneous in their anatomic and electrophysiological properties. ${ }^{4,61}$ The activities of D1 ${ }^{\text {NAc-VP }}$ and D1 NAc-VM MSNs and their projections may be regulated by the different subpopulations of VM DAergic neurons that innervate different subregions of the NAc. Our smFISH data and singlecell sequence show that the expression level of D1 receptor in $D 1^{N A c-V M}-M S N s$ is significantly higher than that of D1 ${ }^{\text {NAc-VP }} M S N s$, suggesting that DA release induce different responses in $D 1^{N A c-V P}$ and D1 $1^{\text {NAc-VM }}$ MSNs and the activation of D1 ${ }^{\text {NAc-VP }}$ neurons may require greater DA release than $D 1^{\mathrm{NAc}-\mathrm{VM}} \mathrm{MSNs}$. In addition, GABAergic, glutamatergic innervation, and others peptide release might produce different influences on D1 $1^{\text {NAc-VP }}$ and D1 $1^{\text {NAc-VM }}$ MSNs as well. ${ }^{62,63}$

Our electrophysiological data showed lower mIPSC frequency and rheobase current in D1 $1^{\text {NAc-VP }}$ neurons than in D1 $1^{\text {NAc-VM }}$ neurons, suggesting less net inhibitory inputs onto D1 ${ }^{\mathrm{NAc}-\mathrm{VP}}$ neurons with more depolarization and high excitability. The monosynaptic inputs to $D 1^{\mathrm{NAc}-\mathrm{VM}}$ and $\mathrm{D} 1^{\mathrm{NAc}-\mathrm{VP}}$ neurons are different in the prefrontal cortex, amygdala, and thalamus. Thus, D1 NAc-VM and D1 ${ }^{\text {NAc-VP }}$ neurons have distinct neural circuits and molecular profiling. The functional divergence between D1 ${ }^{\mathrm{NAc}-\mathrm{VM}}$ and D1 ${ }^{\mathrm{NAc}-\mathrm{VP}}$ neurons may be rooted in their different neural circuits and connectivity.

\section{METHODS}

\section{Animals}

C57BL/6 male mice were purchased from the Shanghai Laboratory Animal Center, CAS. D1-Cre (\#030989-UCD), D2-Cre (\#032108-UCD), D2-eGFP (\#036931-UCD) transgenic mice were purchased from The Mutant Mouse Resource and Research Center. TH-Cre (\#008601), Gad-Cre (\#010802),
vGlut2-Cre mice (\#016963), D1-tdTomato (\#016204) were purchased from The Jackson Laboratory. Mice were group-housed and maintained on a 12 h light-dark cycle (i.e., light cycle; $8 \mathrm{am}-8 \mathrm{pm}$ ) with food and water available ad libitum. 8-12 weeks old mice $(25 \pm 2 \mathrm{~g})$ were used for behavioral experiments. All experiments were performed following the National Institutes of Health Guide for the Care and Use of Laboratory Animals and approved by the Animal Care and Use Committee of Shanghai Medical College of Fudan University.

\section{Preparation of adeno-associated viruses (AAVs)}

The AAV preparation with a titer exceeding $2 \times 10^{12}$ vector genome $(\mathrm{vg})$ $\mathrm{mL}^{-1}$ was used. AAV $V_{9}-E F 1 a-D I O-G C a M P 6 s, A A V_{9}-C A G-D I O-e G F P, A A V_{9}-C A G-$ DIO-tdTomato, $\quad A A V_{9}$-EF1a-DIO-H2B-GFP, AAV ${ }_{9}$-EF1a-DIO-hChR2(H314R)mCherry, $A A V_{9}$-TH-FlpO, AAV ${ }_{9}$-EF1a-DIO-histone-eGFP-2a-TVA, AAV ${ }_{9}$-EF1a$D I O-R V G$ and RV-ENVA-deltaG-dsRed (RVdG $5.0 \times 10^{8}$ colony forming units $(\mathrm{cfu}) / \mathrm{mL}$ ) were generated and packaged by BrainVTA Co., Ltd. AAV $V_{9}$-EF1a-

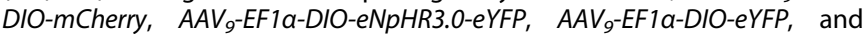
$A A V_{9}-E F 1 a-D I O-G C a M P 6 m$ were generate and packaged by Neuron Biotech co., Ltd. AAV - -hSyn-FLEX-Chrimson-tdTomato, AAV 2 /retro-CAG-FLEX-FlpO,

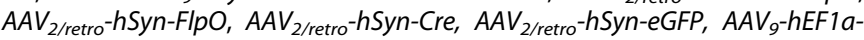
fDIO-hM3D-mCherry, AAV $-h$ Syn-Con/Fon-EYFP, AAV $-h$ Syn-Con/Fon- $h$ ChR2 (H134R)-EYFP, AAV 9 -EF1a-fDIO-hChR2(H314R)-mCherry, AAV 2/retro-EF1a-DIOEYFP, and $A A V_{2 / \text { retro }}-E F 1 a-D I O-m C h e r r y$ were generated and packaged by Taitool Biological Co., Ltd.

\section{Stereotaxic surgery}

Six-week-old mice were anesthetized with isoflurane (3.5\% for induction, $1.5 \%-2 \%$ for maintenance), placed in a stereotaxic instrument (Stoelting Instruments), and injected with 150-200 nL AAV in the targeted brain regions with a 10- $\mu \mathrm{L}$ syringe and a 36-gauge blunt needle under the control of a UMP3 ultra micro pump (World Precision Instruments) at a rate of $50 \mathrm{~nL} / \mathrm{min}$. The needle was left for an additional $5 \mathrm{~min}$ before withdrawal. Mice were remained on a heating pad until fully recovered from anesthesia and given Baytril ( $10 \mathrm{mg}$ per $\mathrm{kg}$, subcutaneously) twice a day for 3 days. Mice were monitored daily and allowed to recover from surgery over 3 weeks before subsequent behavioral experiments.

For the tracer retrograde labeling of $\mathrm{D} 1^{\mathrm{NAc}-\mathrm{VM}}$ and $\mathrm{D} 1^{\mathrm{NAc}-\mathrm{VP}}$ neurons, CTB Alexa Fluor 647 (Thermo Fisher Scientific, Massachussetts, USA. $200 \mathrm{~nL}$ per side, $1 \mu \mathrm{g} / \mu \mathrm{L}$ ) was injected into the VM (AP: $-3.2 \mathrm{~mm}, \mathrm{ML}: \pm 0.4 \mathrm{~mm}$, DV: $-4.4 \mathrm{~mm}$ ) and CTB488 was injected into the VP (AP: $+0.1 \mathrm{~mm}, \mathrm{ML}: \pm 1.2$ $\mathrm{mm}, \mathrm{DV}:-5.1 \mathrm{~mm}$ ) of 8-week-old D1-tdTomato mice. CTB647 (200 nL per side, $1 \mu \mathrm{g} / \mu \mathrm{L}$ ) was injected into the VM, and CTB555 was injected into the VP of 8-week-old D2-eGFP mice. Eleven days after surgery, mice were anesthetized with isoflurane and subject to intra-cardiac perfusion with 30 $\mathrm{mL}$ PBS followed by $50 \mathrm{~mL}$ of $4 \%$ paraformaldehyde (PFA). Coronal sections containing the NAC were sliced at $30 \mu \mathrm{m}$ on a freezing microtome and mounted. Sections were imaged on a confocal (Olympus) with a $10 \times$ and $20 \times$ objective. Cell counting was performed manually with $10 \times$ images. For each mouse, two images per section were obtained at 4 different rostrocaudal coordinates of NAc, providing 8 images per NAc. Total cell counts of 


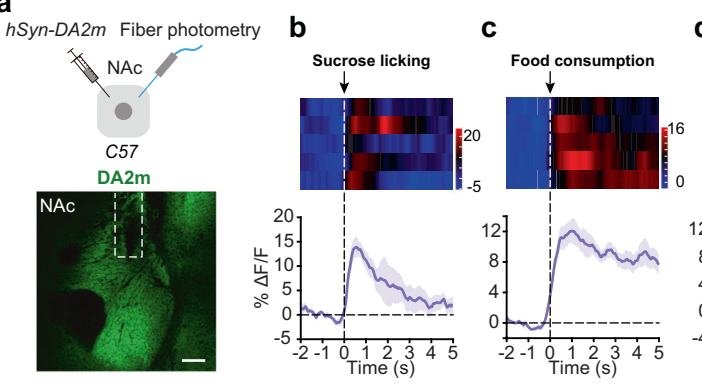

g

DIO-ChR2\&
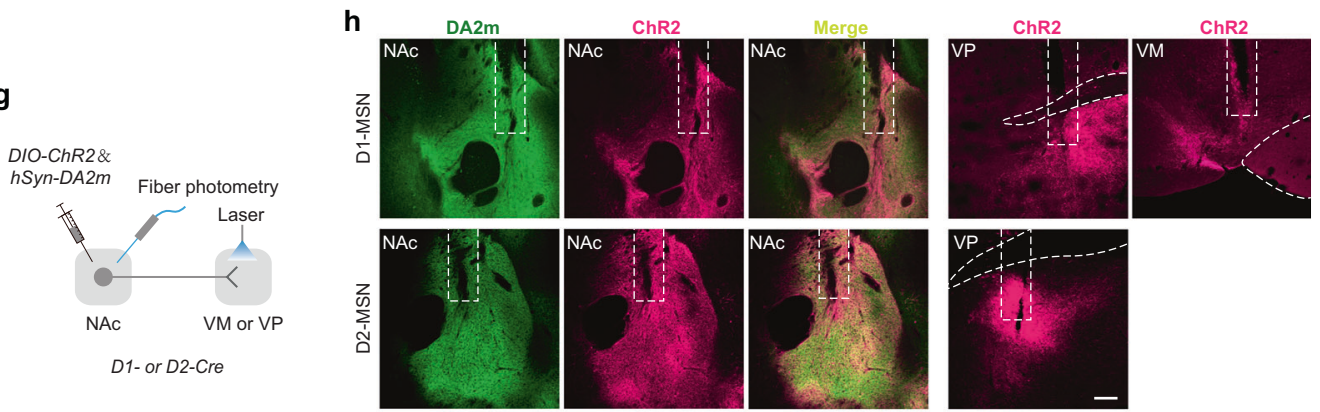

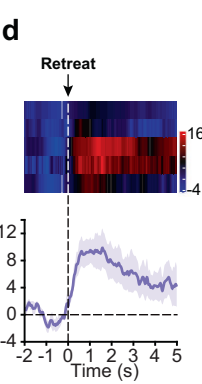

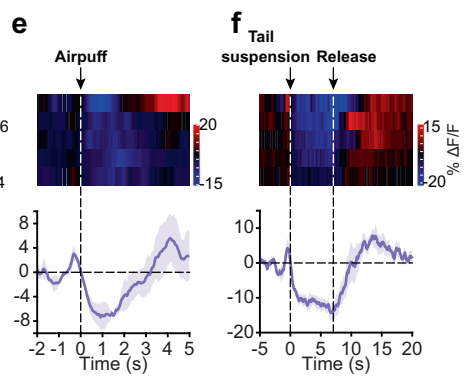

i

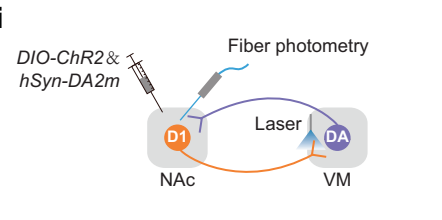

j

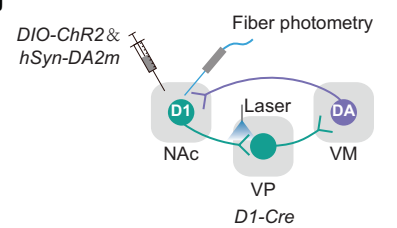

k

Kiber photometry

DIO-ChR2\&
hSyn-DA2m $\sim$
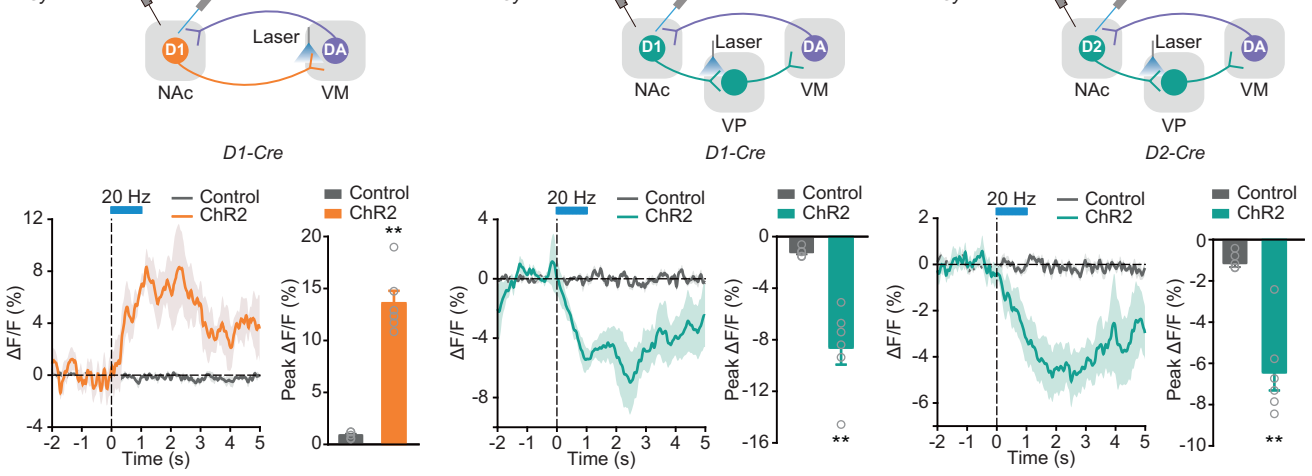

I

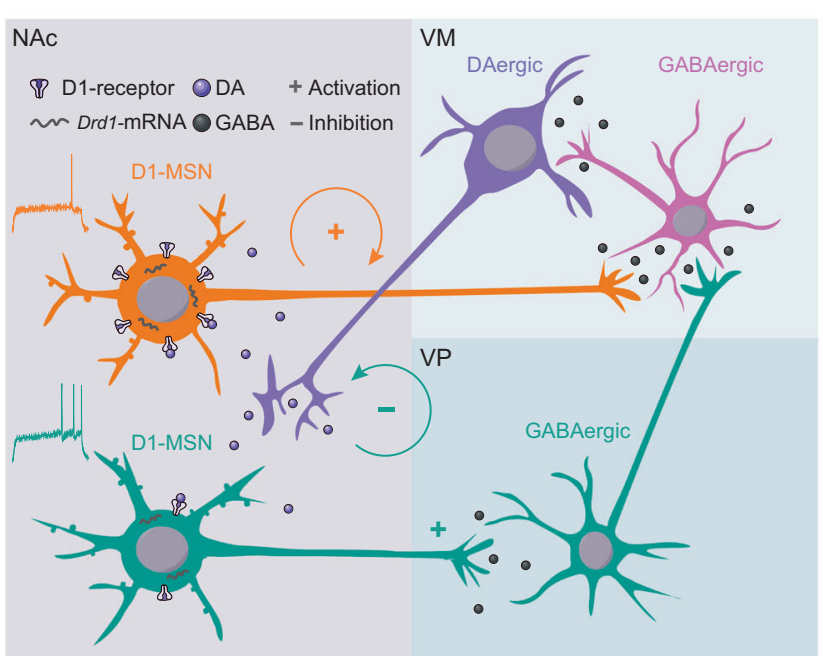

8 images were calculated per mouse. Cell numbers and percentage values were averaged within a section for each mouse and then between mice for the final mean percentage value. Cell counting and colocalization analysis was performed manually with ImageJ $(\mathrm{NIH})$.
For the retrograde labeling of GABA $A^{\mathrm{VP}-\mathrm{VM}}$ or vGlut $2^{\mathrm{VP}-\mathrm{VM}}$ neurons, $A A V$ DIO-H2B-eYFP was injected into the VP and CTB555 (200 $\mathrm{nL}$ per side, $1 \mu \mathrm{g}$ / $\mu \mathrm{L})$ was injected into the VM of Gad-Cre or vGlut2-Cre mice. 4 weeks after injections, brains were perfused and $30 \mu \mathrm{m}$ brain sections were sliced on a 
Fig. 6 Activation of $\mathrm{D1}{ }^{\mathrm{NAc}-\mathrm{VM}}$ pathway increases DA release into the NAC and activation of D1 ${ }^{\text {NAc-VP }}$ pathway produces opposing effect. a-f $A A V-h S y n-D A 2 m$ was infected into the NAc of C57BL/6 mice and an optical fiber was implanted over the NAc to record change of fluorescence of DA sensor DA2m. a Viral infection and representative image of DA2m expression and the location of optical fiber tip in the NAc. b-f Heat map and statistical plot of grouped average DA2m transient for $5 \%$ sucrose licking, sucrose pellet consumption, retreat from the novel object in the approaching-retreat test, unpredictable delivery of air puff, and tail suspension ( $n=5$ mice). g Optical fibers were implanted in the VM/VP and NAc to exert laser stimulation on D1 ${ }^{\mathrm{NAc}-V P}, \mathrm{D} 1^{\mathrm{NAc}-\mathrm{VM}}$, or D2 ${ }^{\mathrm{NAc}-\mathrm{VP}}$ projection and record DA2m signal in the NAC simultaneously. $A A V_{9}-E F 1 a-D I O-h C h R 2-m C h e r r y$ and $A A V-h S y n-D A 2 m$ were infected into the NAc of D1-Cre or D2-Cre mice. h Representative images of DA2m expression and fiber tip location in NAc, and ChR2 labeled axons in the VP and VM. Left: Statistical graph of group average GCaMP responses aligned to optical stimulation $(473 \mathrm{~nm}, 20 \mathrm{~Hz}, 1 \mathrm{~s})$ of D1 ${ }^{\mathrm{NAc}-\mathrm{VM}}(\mathbf{i}), \mathrm{D} 1^{\mathrm{NAc}-\mathrm{VP}}(\mathbf{j})$, or D2 ${ }^{\mathrm{NAc}-\mathrm{VP}}(\mathbf{k})$ projection. Right: bar graph of peak response to optical stimulation [Mann-Whitney $\mathrm{U}$ test: i Control $n=5$, ChrimsonR $n=6, Z=2.739, P=0.0043$; j Control $n=5$, ChR2 $n=6$, $\mathrm{Z}=-2.739, P=0.0043$; $\mathbf{k}$ Control $n=6, \mathrm{ChR} 2 n=6, \mathrm{Z}=-2.882, P=0.0022 ;]^{* *} P<0.01$. I Working model illustrating mesolimbic D1 ${ }^{\mathrm{NAc}-\mathrm{VM}}$ and $\mathrm{D} 1^{\mathrm{NAc}-\mathrm{VP}}$ pathways cooperatively control dopamine balance and reward-aversion state.

freezing microtome. Sections were imaged using a laser-scanning confocal microscope (Olympus) with a $10 \times, 20 \times$ objective, and $40 \times$ oil objective.

For ex vivo electrophysiology experiments, CTB488 or CTB555 (200 nL per side, $1 \mu \mathrm{g} / \mu \mathrm{L})$ were injected bilaterally into the $\mathrm{VP}(\mathrm{AP}:+0.1 \mathrm{~mm}, \mathrm{ML}: \pm 1.2$ $\mathrm{mm}, \mathrm{DV}:-5.1 \mathrm{~mm}$ ) or VM (AP: $-3.2 \mathrm{~mm}, \mathrm{ML}: \pm 0.4 \mathrm{~mm}, \mathrm{DV}:-4.4 \mathrm{~mm})$ of $D 1$ tdTomato or D2-eGFP mice. Electrophysiological experiments were conducted 10 days after CTB injection. In another cohort of mice, $A A V_{2 / \text { retro- }}$ CAG-FLEXFlpO was injected into the VM or VP and $A A V_{9}-E F 1 a-f D I O-h C h R 2(H 314 R)-$ $m$ Cherry was injected into the NAc of 6-week old D1-Cre mice. The functional connectivity of $\mathrm{D} 1^{\mathrm{NAc}-\mathrm{VM}}$ and $\mathrm{D} 1^{\mathrm{NAc}-\mathrm{VP}}$ projectors to the VP were assayed by recording light-evoked responses in the VP cells 4 weeks after AAV injection.

For rabies virus-based monosynaptic tracing, $100 \mathrm{~nL}$ of a 1:1 volume mixture of $A A V_{9}-E F 1 a-D I O-h i s-E G F P-2 a-T V A$ and $A A V_{9}-E F 1 a-D I O-R V G$ was injected into the NAc of D1-Cre mice or the VP of Gad-Cre and vGlut2-Cre mice. Two weeks later, RV-ENVA-deltaG-dsRed was injected into the VP or $\mathrm{VM}$. Then rabies injection mice were housed in P2 lab for 8 days to allow for RVdG spread and dsRed expression. The counting of inputs was conducted blind to the experimental group.

For optical stimulation, $A A V_{9}-E F 1 a-D I O-h C h R 2(H 314 R)-m C h e r r y, A A V_{9^{-}}$ EF1a-DIO-eNpHR3.0-eYFP, or the control virus was injected into the NAC (AP: $+1.8 \mathrm{~mm}, \mathrm{ML}: \pm 0.8 \mathrm{~mm}, \mathrm{DV}:-4.6 \mathrm{~mm})$, and optical fibers $(200 \mu \mathrm{m}$ diameter, 0.37 numerical aperture (NA), Hangzhou Newdoon Technology) were implanted bilaterally above the VP (AP: $+0.1 \mathrm{~mm}, \mathrm{ML}: \pm 2.0 \mathrm{~mm}, \mathrm{DV}$ : $-5.1 \mathrm{~mm}, 10^{\circ}$ angle) or VM (AP: $-3.2 \mathrm{~mm}, \mathrm{ML}: \pm 1.2 \mathrm{~mm}, \mathrm{DV}:-4.5 \mathrm{~mm}, 10^{\circ}$ angle). Fibers were stabilized in place using dental cement.

For the in vivo photometry recording, we recorded calcium fluorescence of D1-MSN terminals in the VM or VP during presenting the rewarding or aversive stimulus in the freely moving mice. $A A V_{9}-E F 1 a-D I O-G C a M P 6 m$ was injected into the NAC (AP: $+1.8 \mathrm{~mm}, \mathrm{ML}: \pm 0.8 \mathrm{~mm}, \mathrm{DV}:-4.6 \mathrm{~mm}$ ), one optical fiber (400 $\mu \mathrm{m}$ diameter, $0.48 \mathrm{NA}$, Hangzhou Newdoon Technology) was implanted into the VM or VP.

To record calcium fluorescence of VM GABAergic or DAergic neurons by stimulation of $\mathrm{D} 1^{\mathrm{NAc}-\mathrm{VM}}$ projection, $A A V_{9}$-hSyn-FLEX-Chrimson-tdTomato was injected into the NAc (AP: $+1.8 \mathrm{~mm}, \mathrm{ML}: \pm 0.8 \mathrm{~mm}, \mathrm{DV}:-4.6 \mathrm{~mm}$ ). Then $A A V_{9}-E F 1 a-D I O-G C a M P 6 s$ were injected into the VM (AP: $-3.2 \mathrm{~mm}$, $\mathrm{ML}: \pm 0.4 \mathrm{~mm}, \mathrm{DV}:-4.4 \mathrm{~mm}$ ) of Gad-Cre mice, or $A A V_{9}-E F 1 a-f D I O-G C a M P 6 s$ and $A A V_{9}-T H-F l p O$ were injected into the VM of D1-Cre mice. Two optic fibers were implanted over the VM. One fiber for optical stimulation (200 $\mu \mathrm{m}$ diameter, $0.37 \mathrm{NA}$, Hangzhou Newdoon Technology) was implanted in the VM with a $10^{\circ}$ angle (AP: $-3.2 \mathrm{~mm}, \mathrm{ML}: \pm 1.2 \mathrm{~mm}, \mathrm{DV}:-4.5 \mathrm{~mm}$ ). Another fiber ( $400 \mu \mathrm{m}$ diameter, $0.48 \mathrm{NA}$, Hangzhou Newdoon Technology) for photometry recording was implanted in the VM (AP: $-3.2 \mathrm{~mm}$, $\mathrm{ML}: \pm 0.4 \mathrm{~mm}, \mathrm{DV}:-4.3 \mathrm{~mm}$ ). This allows us to shine yellow light $(594 \mathrm{~nm})$ into the VM through one optic fiber to activate D1-MSN GABAergic axon terminals arising from the NAc expressing ChrimsonR, while shining low levels of blue light $(473 \mathrm{~nm})$ through the second optic fiber to excite GCaMP6s expressing VM GABAergic or DAergic neurons, and measure emitted green $(525 \mathrm{~nm})$ fluorescence using fiber photometry. ${ }^{64,65}$

To record calcium fluorescence of VM GABAegic and DAergic neurons by stimulation of $\mathrm{D} 1^{\mathrm{NAc}-\mathrm{VP}}$ projection, $A A V_{9}-h$ Syn-DIO-ChR2-mCherry was injected into the NAc. Then $A A V_{9}$-EF1a-DIO-GCaMP6s were injected into the VM (AP: $-3.2 \mathrm{~mm}, \mathrm{ML}: \pm 0.4 \mathrm{~mm}$, DV: $-4.4 \mathrm{~mm}$ ) of Gad-Cre mice, or $A A V_{9}-E F 1 a-f D I O-G C a M P 6 s$ and $A A V_{9}-T H-F I p O$ were injected into the VM of $D 1-C r e$ mice. One optic fiber for optical stimulation was implanted in the VP (AP: $+0.1 \mathrm{~mm}, \mathrm{ML}: \pm 1.2 \mathrm{~mm}$, DV: $-5.1 \mathrm{~mm}$ ), and another optic fiber for photometry recording was implanted over the VM.

\section{Ex vivo electrophysiology}

Brain tissue preparation. Living acute brain slice preparation for electrophysiological recording was performed as previously described. ${ }^{66}$ Mice were anaesthetized with isoflurane $3.5 \%$ induction, $1.5 \%-2 \%$ maintenance) and perfused transcardially with $20 \mathrm{ml}$ ice-cold and oxygenated $\left(95 \% \mathrm{O}_{2}, 5 \% \mathrm{CO}_{2}\right)$ cutting solution containing (in $\mathrm{mM}$ ): 93.0 NMDG, 93.0 $\mathrm{HCl}, 2.5 \mathrm{KCl}, 1.2 \mathrm{NaH}_{2} \mathrm{PO}_{4}, 30.0 \mathrm{NaHCO}_{3}, 20.0$ HEPES, 25.0 Glucose, 5.0 Sodium ascorbate, 2.0 Thiourea, 3.0 Sodium pyruvate, $10.0 \mathrm{MgSO}_{4}, 0.5$ $\mathrm{CaCl}_{2}$ ( $\left.\mathrm{pH} 7.3-7.4,295-305 \mathrm{mOsm}\right)$. The brains were rapidly removed and placed in ice-cold and oxygenated cutting solution. The coronal slices $(300 \mu \mathrm{m})$ containing the NAC were prepared with a semiautomatic vibrating blade microtome (HM760V, Thermo) and then transferred to the incubation chamber at $32{ }^{\circ} \mathrm{C}$ with the oxygenated cutting solution for $12 \mathrm{~min}$. After the initial recovery period, the slices were kept in the modified aCSF containing (in mM): $94.0 \mathrm{NaCl}, 2.5 \mathrm{KCl}, 1.2 \mathrm{NaH}_{2} \mathrm{PO}_{4}, 30.0$ $\mathrm{NaHCO}_{3}, 20.0$ HEPES, 25.0 Glucose, 5.0 Sodium ascorbate, 2.0 Thiourea, 3.0

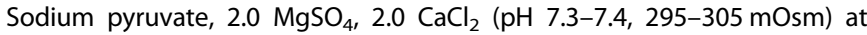
room temperature under constant carbogenation. For whole-cell patchclamp recording, the slices were transferred to the recording chamber perfused with $32{ }^{\circ} \mathrm{C}$ carbogenated recording aCSF containing (in $\mathrm{mM}$ ): $124.0 \mathrm{NaCl}, 2.5 \mathrm{KCl}, 1.2 \mathrm{NaH}_{2} \mathrm{PO}_{4}, 30.0 \mathrm{NaHCO}_{3}, 20.0$ HEPES, 25.0 Glucose, 5.0 sodium ascorbate, 2.0 Thiourea, 3.0 sodium pyruvate, $2.0 \mathrm{MgSO}_{4}, 2.0$ $\mathrm{CaCl}_{2}(\mathrm{pH} 7.3-7.4,295-305 \mathrm{mOsm})$ at a rate of $1.5 \mathrm{~mL} / \mathrm{min}$.

Measurements of intrinsic membrane properties. The recording electrodes (4-6 $\mathrm{M} \Omega$ resistance) were filled with an internal solution containing (in mM) 120.0 K-gluconate, $5.0 \mathrm{NaCl}, 1.0 \mathrm{MgCl} 2,0.2 \mathrm{EGTA}, 10.0$ HEPES, 2.0 MgATP, and 0.1 NaGTP (adjusted to pH 7.2 with $\mathrm{KOH}, 280-290 \mathrm{mOsm}$ ). After recording the resting membrane potential of each neuron, the slow polarizing current was applied to hold the neurons at $-70 \mathrm{mV}$. To measure the firing frequency of action potentials, depolarizing current steps (from 0 to $200 \mathrm{pA}$ in $20 \mathrm{pA}$ increment, 1-s duration per each step) were applied. After completion of the current step, an additional depolarizing current step (in 5 pA unit increment) was injected again to find rheobase. ${ }^{67,68}$ The intrinsic membrane properties were analyzed with Clampfit (Clampfit 10.2). Spontaneous EPSCS and IPSCs. For recording miniature excitatory postsynaptic currents (mEPSCs) and miniature inhibitory postsynaptic currents (mIPSCs), patch electrodes were filled with an internal solution containing (in mM) $120.0 \mathrm{CsMeSO}_{4}, 15.0 \mathrm{CsCl}, 10.0 \mathrm{TEA}-\mathrm{Cl}, 8.0 \mathrm{NaCl}, 10.0 \mathrm{HEPES}, 0.2$ EGTA, 4.0 MgATP, $0.3 \mathrm{NaGTP}$, and 5.0 QX-314 (pH 7.3, 280-290 mOsm). mEPSCs (> 300 events per cell) were collected at $-70 \mathrm{mV}$ in the presence of TTX (Tetrodotoxin, $1 \mu \mathrm{M})$, picrotoxin $(100 \mu \mathrm{M})$, and D-AP5 (D-2-amino-5phosphono-valeric acid, $50 \mu \mathrm{M})$. mIPSCs were collected at $0 \mathrm{mV}$ in the presence of TTX $(1 \mu \mathrm{M})$, D-AP5 $(50 \mu \mathrm{M})$ and NBQX (2,3-dihydroxy-6-nitro-7sulfamoyl-benzo(f)quinoxaline, $100 \mu \mathrm{M})$. The signals were acquired at 20 $\mathrm{kHz}$ and filtered at $2 \mathrm{kHz}$. The series-resistance was $<20 \mathrm{MOhm}$. mEPSCs and mIPSC were analyzed with Minianalysis (Synaptosoft). ${ }^{69,70}$

PPRs. The internal solution containing (in $\mathrm{mM}$ ) $120 \mathrm{KCl}, 30$ potassium gluconate, $4.0 \mathrm{MgCl}_{2}$, 10 sodium creatine phosphate, 1.1 EGTA, 5 HEPES, 3.4 NaATP, and 0.1 NaGTP (adjusted to pH 7.2 with $\mathrm{KOH}, 280-290$ mOsm). Lightevoked IPSCs were evoked by 4-ms-long LED pulse that was transmitted on the slice through the light path of the microscope and recorded in the presence of TTX $(1 \mu \mathrm{M})$, D-AP5 $(50 \mu \mathrm{M})$, and NBQX $(100 \mu \mathrm{M})$ at $-70 \mathrm{mV}$ in voltage-clamp model. PPRs were obtained $5 \mathrm{~min}$ after invading the cell at an interval of $50 \mathrm{~ms}$ for 30 consecutive traces. The PPR was calculated as the peak amplitude ratio of the second to the first IPSC. ${ }^{10,50}$

Photostimulation of brain slices. To test spike fidelity of optogenetic stimulation of ChR2 and inhibitory effects of eNphR3.0, brain slices containing the NAc were chosen for current-clamp recording with the internal solution containing (mM): $120.0 \mathrm{~K}$-gluconate, $5.0 \mathrm{NaCl}_{1} 1 \mathrm{MgCl}_{2}, 0.2$ EGTA, 10.0 HEPES, 2.0 MgATP, and 0.1 NaGTP (adjusted to $\mathrm{pH} 7.2$ with $\mathrm{KOH}$, 
280-290 mOsm). Blue light ( $473 \mathrm{~nm}$; duration $5 \mathrm{~ms}$; intensity $\sim 3 \mathrm{~mW}$ ) was delivered at the frequency of $5 \mathrm{~Hz}, 10 \mathrm{~Hz}, 20 \mathrm{~Hz}$ to trigger the action potential. Yellow light $(594 \mathrm{~nm}$, intensity $\sim 3 \mathrm{~mW}$ ) was delivered to eliminate the action potential induced by $100 \mathrm{pA}$ current stimulation. To measure the function and specificity of CNO stimulation of hM3Dq in D1MSNs, brain slices containing the NAc were chosen for current-clamp recording. Rheobase was defined as the minimal current amplitude required for firing an action potential with a depolarizing current step (in 5 pA unit increment) and measured before and $15 \mathrm{~min}$ after CNO application to the bath solution $(5 \mu \mathrm{M})$.

During the execution and analysis of the electrophysiological recordings, the experimenter was blind to the genotypes of the individual animals. The signals were acquired at $20 \mathrm{kHz}$ and filtered at $2 \mathrm{kHz}$. The series-resistance was $<20 \mathrm{MOhm}$. Data with series resistance changed by $>20 \%$ were excluded. mEPSCs and mIPSCs were analyzed using Minianalysis. The spike frequency, rheobase, and PPRs were analyzed using Clampfit.

\section{Behavioral scheme}

Conditioned place preference/avoidance (CPP/CPA). CPP/CPA was performed as previously reported. ${ }^{71}$ The optical fiber was connected to a fiberoptic cable and mice were placed in a rectangular apparatus consisting of left and right chambers $(15 \mathrm{~cm} \times 15 \mathrm{~cm}$ each). One chamber had black and white striped walls and frosted floor and the other had black and white checkered walls and black floor. Before behavioral sessions, mice were gently attached to a fiberoptic patch cord with optical fiber via a ceramic sleeve (Hangzhou Newdoon Technology). The patch cable was also connected to a fiberoptic rotary joint (Doric Lenses), which permitted free rotation while transmitting light from an upstream 473/594 nm DPSS laser diode (Shanghai Dream Lasers Technology Co., Ltd.), and laser output was controlled using a mini-Master pulse stimulator (Thinker Teck Nanjing Biotech). Power output was tested at the tip of optic fiber and was checked before and after each experimental animal. On day 1, mice were allowed to explore the entire apparatus for $15 \mathrm{~min}$. On days $2-4$, mice were confined to one of the chambers paired with optical stimulation (ChR2: $473 \mathrm{~nm}, 10$ $\mathrm{mW}$, a train of twenty 5-ms light pulses at $20 \mathrm{~Hz}$ every $10 \mathrm{~s}$; eNpHR3.0: 594 $\mathrm{nm}, 5 \mathrm{~mW}, 3-\mathrm{min}$ epochs with 3-min intervals for 30-min) in the morning and confined in the other chamber for $30 \mathrm{~min}$ without optical stimulation in the afternoon. Mice were presented with two conditioning trials for 30 min separated by $6 \mathrm{~h}$ each day. The laser or no laser paired conditioning was performed alternatively in the morning or afternoon and repeated for 3 days. On day 5 mice were allowed to freely explore the entire apparatus for $15 \mathrm{~min}$. A video camera positioned above the chamber recorded the trial, and mouse locations were tracked and analyzed using Ethovision XT software (Noldus, Wageningen, Netherlands). CPP scores were calculated by subtracting the time spent in the non-stimulated side from the time spent in the stimulated side.

To investigate the effects of activation or suppression of $D 1^{\mathrm{NAc}-\mathrm{VM}}$ and $\mathrm{D} 1^{\mathrm{NAc}-\mathrm{VP}}$ projections on cocaine-CPP and LiCl-CPA, optical fibers were connected to the cannula before injection of saline or cocaine $(10 \mathrm{mg} / \mathrm{kg})$ or $\mathrm{LiCl}(150 \mathrm{mg} / \mathrm{kg})$ and perform the optical stimulation during cocaine or $\mathrm{LiCl}$ conditioning with the protocol as described as above. No laser stimulation was presented during saline conditioning. Cocaine/LiCl and saline paired conditioning was performed alternatively in the morning or afternoon and repeated for 3 days. On day 5 mice were allowed to freely explore the entire apparatus for $15 \mathrm{~min}$. A video camera positioned above the chamber recorded the trial, and mouse locations were tracked and analyzed using Ethovision XT software (Noldus, Wageningen, Netherlands).

The rewarding or aversive magnitude of optical activation of $D 1^{\mathrm{NAc}-\mathrm{VM}}$ and $\mathrm{D} 1^{\mathrm{NAc}-\mathrm{VP}}$ projections was examined with cocaine CPP or $\mathrm{LiCl}$ CPA paradigm. The mice were conditioned with saline injection on one side and cocaine injection on the other side of the chamber. Optical activation of $D 1^{\mathrm{NAc}-\mathrm{VM}}$ projection was presented during saline conditioning. Another cohort of mice was conditioned with saline injection on one side and $\mathrm{LiCl}$ injection on the other side. Optical activation of $\mathrm{D} 1^{\mathrm{NAc}-\mathrm{VP}}$ projection was presented during saline conditioning. Cocaine/LiCl and saline paired conditioning was performed alternatively in the morning or afternoon and repeated for 3 days. One day later the mice were allowed to freely explore the entire apparatus for $15 \mathrm{~min}$.

Real-time place preference/avoidance testing (RTPP/A). Mice were placed in a rectangular apparatus consisting of left and right chambers $(15 \mathrm{~cm} \times$ $15 \mathrm{~cm}$ each). Mice were allowed free moving between compartments for $20 \mathrm{~min}$. Each entry into the same chamber was paired with optical stimulation (ChR2: $473 \mathrm{~nm}, 10 \mathrm{~mW}, 5 \mathrm{~ms}$ pulses at $20 \mathrm{~Hz}$ upon entry).
A video camera positioned above the chamber recorded each trial and mouse locations were tracked and analyzed by Ethovision XT software (Noldus, Wageningen, Netherlands). Difference scores were calculated by subtracting the time spent in the non-stimulated chamber from the time spent in the stimulated chamber.

ICSS. ICSS was performed as previously reported. ${ }^{40,72}$ Mice were placed into soundproofing operant chambers $(24 \mathrm{~cm} \times 20 \mathrm{~cm} \times 18 \mathrm{~cm}, \mathrm{~L} \times \mathrm{W} \times \mathrm{H}$, Shanghai VanBi Intelligent Technology Co., Ltd.) containing two illuminated nose-poke ports ("active" and "inactive"). A nose-poke response to the active port was accompanied by illumination of cue-light and delivery of optical stimulation (ChR2: $473 \mathrm{~nm}, 10 \mathrm{~mW}, 5 \mathrm{~ms}$ pulses at $20 \mathrm{~Hz}, 1 \mathrm{~s}$ duration), while a nose-poke response in the "inactive" port resulted in no optical stimulation or cue-light delivery. Light stimulation was controlled by a computer running Tracking Master V3.0 software (Shanghai VanBi Intelligent Technology Co., Ltd.), which recorded times of nosepoke.

Intra-cranial light administration in specific subarea (ICLASS). ICLASS was performed as previously reported. ${ }^{73}$ An illuminated open field $(40 \mathrm{~cm} \times 40$ $\mathrm{cm}, \mathrm{L} \times \mathrm{W}$ ) was used for this behavioral experiment. Within the open field, red lines marked a central area $(20 \mathrm{~cm} \times 20 \mathrm{~cm}, L \times W)$. Before behavioral sessions, mice were gently attached to a fiber optic patch cord with optical fiber via a ceramic sleeve (Hangzhou Newdoon Technology). Optical stimulation was controlled by a computer running Ethovision XT software (Noldus, Wageningen, Netherlands), which videotaped and analyzed location and movements in the central and the periphery arena. The ICLASS task began 3 weeks after AAV injection. The mouse was gently released from the center of the open field and allowed for exploration for $15 \mathrm{~min}$, and the locomotion was monitored and calculated. Whenever the centroid of the mouse body was located within the central or the periphery arena, blue light pulses were passed to the D1 $1^{\mathrm{NAc}-\mathrm{VM}}$ and D1 $1^{\mathrm{NAc}-}$ VP projections through the optical fiber (ChR2: $473 \mathrm{~nm}, 10 \mathrm{~mW}, 5 \mathrm{~ms}$ pulse at $20 \mathrm{~Hz}$ upon entry). Mouse movements and the percent ratio of the time spent in the central and the periphery arena were tracked and analyzed by Ethovision XT software (Noldus, Wageningen, Netherlands).

\section{Fiber photometry recording}

Response to sucrose licking. Delivery of water was controlled by a microcontroller-based behavioral system running on Tracking Master V3.0 software (Shanghai VanBi Intelligent Technology Co., Ltd.). Licks were detected by a custom-made lickometer with a capacitive touch sensor and a microcontroller. Fiber photometry was performed as previously reported. ${ }^{47}$ Before recording day, mice were water-deprived for $12 \mathrm{~h}$, Then they were introduced to sucrose licking chamber. $20 \mu \mathrm{L}$ water was delivered by the lick of the water spout followed with a 10-s timeout. The onset of each licking behavior was tagged by triggering TL signal (Shanghai VanBi Intelligent Technology Co., Ltd.), which was synchronously output to the fiber photometry system. The TTL signal and fluorescence signal were recorded simultaneously by a fiber photometry system (Thinker Tech Nanjing Biotech). Mouse behaviors and fluorescence signals were captured simultaneously. Fluorescence signals during the first five times of licking behavior of each mouse were analyzed.

Response to retreat behavior. Mice were habituated to a rectangular openfield with a video capture system $\left(40 \times 40 \times 40 \mathrm{~cm}^{3}, \mathrm{~L} \times \mathrm{W} \times \mathrm{H}\right.$, Shanghai VanBi Intelligent Technology Co., Ltd.) 30 min per day for 3 days. After this habituation session, mice were exposed to the chamber for $10 \mathrm{~min}$, then a novel object was introduced into the center. Mouse behaviors and fluorescence signals were captured simultaneously. The first three retreat behaviors were manually tagged through videos by researchers blind to the experiment groups and averaged to obtain a time-locked response. ${ }^{21}$

Response to sucrose pellet consumption. Mice with free access to food and water were subjected to photometry recording during consumption of sucrose pellet (Bio-Serv, Co., Flemington, NJ, USA, F07595). The mice were habituated to a rectangular chamber with a video capture system $\left(20 \times 10 \times 20 \mathrm{~cm}^{3}, \mathrm{~L} \times \mathrm{W} \times \mathrm{H}\right.$, Shanghai VanBi Intelligent Technology Co., Ltd.) $30 \mathrm{~min}$ per day for 3 days. A dish of sucrose pellets (MLabRodent Tablet 20MG; TestDiet) was introduced into one corner of the chamber. Then the mice were introduced to the chamber. Mouse behaviors and fluorescence signals were captured simultaneously. Fluorescence signals during the first three to five times of consumption behavior of each mouse were analyzed. 
Response to social interaction. The mice were habituated to a rectangular open-field with a video capture system $\left(40 \times 40 \times 40 \mathrm{~cm}^{3}, \mathrm{~L} \times \mathrm{W} \times \mathrm{H}\right.$, Shanghai VanBi Intelligent Technology Co., Ltd.) 30 min per day for 3 days. After the habituation session, mice were exposed to the open-field for 10 min, then a female stranger mouse ( 6 weeks old) was introduced into the open-field. The social behaviors and fluorescence signals were captured simultaneously. Sniffing female refers to the time in which the male's nose is coming closely toward the female's face and/or body. Fluorescence signals during sniffing the female mouse were analyzed.

Response to unexpected air puff. Animals were introduced into a previously familiar chamber $\left(40 \times 40 \times 40 \mathrm{~cm}^{3}, \mathrm{~L} \times \mathrm{W} \times \mathrm{H}\right)$. In a single experimental session, ten unexpected air puffs were randomly delivered to the eye of mice with inter-trial intervals of $1 \mathrm{~min}$ to $5 \mathrm{~min}$. All the mice underwent sucrose licking trials, the retreat behavior next, and then the unexpected air puff to minimize the possible effect of the previous stimulus on subsequent experiments. Mouse behaviors and fluorescence signals were captured simultaneously. The onset of each air puff was recorded by the performer and manually tagged through videos by students blind to the experimental groups. Fluorescence signals during the first five times of air puff of each mouse were analyzed.

Response to tail suspension. Animals were introduced into the same chamber $\left(40 \times 40 \times 40 \mathrm{~cm}^{3}, \mathrm{~L} \times \mathrm{W} \times \mathrm{H}\right)$. After sucrose consumption trials, the retreat behavior next, and then the unexpected air puff, tail suspension was delivered 10 times with inter-trial intervals of $1 \mathrm{~min}$ to $5 \mathrm{~min}$. The tail of mice was chased and grabbed by hand. We grabbed and suspended the tail of the tested mice fast to reduce the interference of irrelevant stimuli. The height of tail suspension was about $40 \mathrm{~cm}$ height from the bottom of the chamber. After grabbing, the mice were suspended in air for $7 \mathrm{~s}$ or $10 \mathrm{~s}$ before releasing them in the chamber. Mouse behaviors and fluorescence signals were captured simultaneously. The onset of each tail suspension was recorded by the performer and manually tagged through videos.

Response to cocaine conditioning, cocaine CPP test, and optical stimulation induce CPP/A test. Animals were acclimated to the behavior room before conditioning. A 1-m-long fiber-optic patch cord (Doric Lenses) was connected to the implanted optical fiber targeting the VM or VP with a zirconia sheath and was suspended above the experimental environment to allow animals to move freely. In cocaine-CPP task, fluorescence signals were captured during the first pair of saline and cocaine conditioning, and CPP test. In optical stimulation induce CPP/A task, fluorescence signals were captured during CPP/A test. The signals during conditioning and entrances to the cocaine or stimulation paired side were analyzed.

Photometry recording for DA release. Mice were placed into a chamber with a patch cord and subjected to sucrose consumption, retreat behavior, unexpected air puff, and tail suspension for recording DA-sensor signals. The stimuli were delivered as mentioned above. For stimulation of D1-MSN or D2-MSN terminals in the VM or VP, optical stimulation $(473 \mathrm{~nm}, 10 \mathrm{~mW}$, $5 \mathrm{~ms}$ pulse at $20 \mathrm{~Hz}, 1 \mathrm{~s}$ duration) was given every $10-30 \mathrm{~s}$ for 10 trials through one optic fiber implanted in the VM or VP. The other fiber planted in the NAc was used for both exciting and recording from the genetically encoded indicator of DA-sensor (DA2m) in real-time.

Fiber photometry analysis. The laser power was adjusted at the tip of optical fiber to the low level of $10-20 \mu \mathrm{W}$, to minimize bleaching. The GCaMP or DA-sensor signal was collected and converted to voltage signals. The analog voltage signals were digitalized at $100 \mathrm{~Hz}$ and recorded by a fiber photometry system developed by Dr. Luo's lab ${ }^{74,75}$ (Thinker Tech Nanjing Biotech). The data were segmented based on behavioral events within individual trials. For recording the response of axon-GCaMP and $\mathrm{DA} 2 \mathrm{~m}$ to the stimuli in free-moving mice, fluorescence values were obtained before the stimuli and during sucrose licking, sucrose pellet consumption, sniffing of the female stranger, retreat from the novel object in the center, airpuff $(0-5 \mathrm{~s})$ and tail suspension $(0-10 \mathrm{~s})$. The data were segmented based on behavioral events within individual trials. $\Delta \mathrm{F} / \mathrm{F}$ of the 2 -s before stimulation were taken as the baseline. The in vivo fiber photometry recordings were analyzed by the students blind to the experimental group. Photometry data were analyzed with custom-written MATLAB codes (MATLAB R2019b, MathWorks). The frequency of $\mathrm{Ca}^{2+}$ transient events in $\mathrm{D} 1^{\mathrm{NAc}-\mathrm{VM}}$ and $\mathrm{D} 1^{\mathrm{NAc}-\mathrm{VP}}$ projectors during cocaine conditioning was analyzed as the previous study. ${ }^{76}$ In brief, fluorescence signals were normalized $(\Delta \mathrm{F} / \mathrm{F})$ during a $20 \mathrm{~s}( \pm 10 \mathrm{~s})$ window around each data point. A value of 2.91 median absolute deviations of baseline before drug treatment was used as a threshold for detecting events during 5-10 min after saline or cocaine injection during conditioning.

\section{Single-cell RNA sequencing}

Neuronal isolation of the fluorescence-labeled cell. C57 mice (8 weeks) were injected with CTB555 in the VP or VM. Eleven days after CTB labeling, mice were processed to a single cell suspension as the previous research. ${ }^{77}$ Briefly, mice were anesthetized with isofluorane $3.5 \%$ for induction, $1.5-2 \%$ for maintenance) and then decapitated. The brain was quickly removed and transferred to cold ACSF bubbled with carbogen $\left(95 \% \mathrm{O}_{2} / 5 \% \mathrm{CO}_{2}\right)$ for $5 \mathrm{~min}$ before being sectioned into $300 \mu \mathrm{m}$ sections with a vibratome. NAc area was collected and digested in Hibernate-A medium containing $10 \mathrm{U} / \mathrm{mL}$ Papain and $100 \mathrm{U} / \mathrm{mL}$ DNAse I at $28^{\circ} \mathrm{C}$ for 5 min with gentle trituration. The suspension was then filtered with a 40 $\mu \mathrm{m}$ mesh and purified with percoll gradient. Then the cells were resuspended in Hibernate-A medium with $0.04 \%$ BSA and kept on ice. The $\mathrm{CTB}_{5} 55^{+}$cells were picked up manually under a fluorescence microscope. Bilateral NAc from five mice each group was used for this experiment.

Single-cell RNA-seq library preparation. Single-cell transcriptional profiling was performed following the methods from Tang et al. ${ }^{78}$ Single cells were picked into the cell lysis buffer containing barcoded reverse transcription primers by mouth pipette. Reverse transcription and amplification were performed as described for Smartseq2, except that a second-round amplification was performed using $3^{\prime}$ biotinated primer. Then the PCR products with different barcodes were pooled together, sonic disrupted into $\sim 300 \mathrm{bp}$ fragments, 3' enriched, and then used for library construction. The libraries were processed on the Illumina platform for sequencing of 150 bp pair-end reads, approximatively $500 \mathrm{M}$ raw data were acquired for each cell.

By retrograde tracing as mentioned above, we manually isolated retrograde-labeled NAc cells projecting from VP and VM pathways under fluorescence microscope, and performed single-cell transcriptome sequencing. In three independent experiments, 478 cells from VP group (NAc $\rightarrow$ VP), and 214 cells from VM group (NAc $\rightarrow$ VP) were collected. We assessed cDNA size (Supplementary information, Fig. S7a), sequencing saturation status (Supplementary information, Fig. S7b), genes detected (Supplementary information, Fig. S7c) to evaluate library quality, which all met conventional Smart-seq2 standards. ${ }^{79}$ Data from Ho et al. and Gokce et al. were also included to aid data quality evaluation and cell-type clustering. From the 692 cells analyzed, 562 were neurons, characterized by comparing with annotated data from Gokce et al. Then we utilized striatal single-cell data from $\mathrm{Ho}$ et al., in which D1 and D2-positive cells from transgenic mice were manually isolated and sequenced, to see if there was spatial separation of D1 and D2 cells based on UMAP (Uniform Manifold Approximation and Projection) clustering. As there was no clear segregation of these MSNs, we simply picked out 209 Drd1-expressing cells for further analysis, in which 131 cells were NAc $\rightarrow V P$, and 78 were $\mathrm{NAc} \rightarrow \mathrm{VM}$.

Single-cell RNA-seq analysis. Raw sequences were demultiplexed using zUMI software ${ }^{80}$ and then aligned to the Ensembl mouse genome (GRCm38) with STAR (version 2.7.0a).81 Raw count for each gene was used for subsequent major cell type determination using Seurat, ${ }^{82}$ and DESeq $2^{83}$ was used for within-cluster differential gene expression analysis. ClusterProfiler ${ }^{84}$ was used to analyze gene ontology enrichment.

\section{Immunofluorescence}

Mice were transcardially perfused with $0.9 \%$ saline followed by $4 \%$ PFA (dissolved in $0.1 \mathrm{M} \mathrm{Na}_{2} \mathrm{HPO}_{4} / \mathrm{NaH}_{2} \mathrm{PO}_{4}$ buffer, pH 7.5). Brains were postfixed in $4 \%$ PFA at $4{ }^{\circ} \mathrm{C}$ for $4 \mathrm{~h}$ and then transferred to $30 \%$ sucrose/PBS solution for 3 days. Then brains were sectioned into $30-\mu \mathrm{m}$-thick slices, which were then stored in the cryoprotective buffer at $-20^{\circ} \mathrm{C}$. For immunostaining, each slice was placed in PBS and washed three times in PBS, followed by incubation with primary antibody (anti- $\mathrm{TH}^{85}$ rabbit, 1:1,000, Millipore $\mathrm{AB} 152$ ) at $4{ }^{\circ} \mathrm{C}$ overnight. After being rinsed in with PBS, the brain slices were incubated with fluorescence conjugated secondary antibody Alexa-647 (rabbit, 1:50000, Jackson ImmunoResearch) at room temperature for $2 \mathrm{~h}$. Finally, slices were coverslipped with the anti-quenching mounting medium (Thermo Fisher Scientific). 


\section{FISH by RNAscope}

Three weeks after injection of $A A V_{2 / \text { retro }}$-hSyn-eGFP in the VM or VP of C57 mice, the mice were perfused intracardiacally with saline first, then with $4 \%$ PFA in $0.1 \mathrm{M} \mathrm{Na}_{2} \mathrm{HPO}_{4} / \mathrm{NaH}_{2} \mathrm{PO}_{4}$ buffer ( $\mathrm{pH} 7.5$ ) and the brains were removed. After post-fixation in $4 \%$ paraformaldehyde for $4 \mathrm{~h}$, the samples were stored in 30\% sucrose/PBS for 3 days. FISH was performed on the fixed frozen brain slices containing the NAc with $10-\mu \mathrm{m}$ thick slices, following the RNAscope procedures (Advanced Cell Diagnostics, Inc., Newark, CA, USA). In brief, frozen sections were cut coronally through the NAc formation. Sections were thaw-mounted onto Superfrost Plus Microscope Slides (Fisher Scientific, Waltham, USA) and pretreated for protease digestion for $10 \mathrm{~min}$ at room temperature. Sections from $A A V_{2 /}$ retro-hSyn-eGFP injection mice were then incubated with probes of mouse Drd 1 and Markers for $2 \mathrm{~h}$ at $40^{\circ} \mathrm{C}$ with labeled probe mixture per slide (Drd1, accession No: NM_010076.3, target region 444-1358; Drd2, accession No: NM_010077.2, target region 69-1175; Markers: Tac1, accession No: NM_009311.2, target region 20-1034; Pdyn, accession No: NM_018863.3, target region 33-700; Chrm4, accession No: NM_007699.2, target region 400-1330; Is/1, accession No: NM_021459.4, target region 145-1437; Slc35d3, accession No: NM_029529.3, target region 455-1603; Penk, accession No: NM_001002927.2, target region 106-1332; Adk, accession No: NM_134079.4, target region 152-1137, Adora2a, accession No: NM_009630.2, target region 152-1222; Gpr6, accession No: NM_199058.1, target region 138-1027; Gpr52, accession No: NM_001146330.1, target region 4-981; Foxp1 accession No: NM_053202.2, target region 1101-2194; Htr7, accession No: NM_008315.2, target region 1516-2490; Sp9, accession No: NM_001005343.2, target region 2-960; Arc, accession No: NM_018790.2, target region 23-1066; EYFP, accession No: KF450806.1, target region 7768-8420; mCherry, accession No: MH492388.1, target region 23-681). The nonspecifically hybridized probe was removed by washing the sections in $1 \times$ washing buffer at room temperature, followed by Amplifier 1-FL for $30 \mathrm{~min}$, Amplifier 2-FL for $30 \mathrm{~min}$ and Amplifier 3-FL for $15 \mathrm{~min}$ at $40^{\circ} \mathrm{C}$. Each amplifier was removed by washing with $1 \times$ washing buffer for $2 \mathrm{~min}$ at room temperature. At least six brain slices from each mouse were performed RNAscope and imaged.

\section{Confocal microscopy and image analysis}

Confocal fluorescence images were acquired with Nikon A1 confocal laser scanning microscope using a $10 \times$ or $20 \times$ objective for imaging stained or autofluorescent neurons. The center of the viral infection was taken at the brightest fluorescent point. The tip of the fiber or cannulas was determined by the $\sim 50 \mu \mathrm{m}$ thick gliosis generated by the fiber.

Cell counting was conducted using Image J. Brain regions were defined regarding the Allen Mouse Brain Reference Atlas, the areas were quantified by applying the scale calibration. FISH images of co-localization of eGFP/ Drd1/Marker cells were determined using confocal images of the NAC in 6 slices per brain. The number of triple-positive cells was divided by the number of double-positive cells (eGFP/Drd $1^{+}$) as the expression levels in $\mathrm{D} 1^{\mathrm{NAc}-\mathrm{VP}}$ and D1 $1^{\mathrm{NAc}-\mathrm{VM}}$ MSNs. The counting was done by an experimenter blind to the groups.

FISH images of Drd 1 expression in the D $1^{\mathrm{NAc}-\mathrm{VP}}$ and $\mathrm{D} 1^{\mathrm{NAc}-\mathrm{VM}}$ neurons were analyzed using custom MATLAB as previously described. ${ }^{86}$ Briefly, six slices from each mouse containing NAc were used. DAPI staining was used to localize cell bodies. Puncta of FISH molecules were counted within Drd1 and eGFP double-positive cells. FISH images of Arc and KIf5 expression in the D1 ${ }^{\mathrm{NAc}-\mathrm{VP}}\left(\right.$ EYFP $\left.^{+}\right)$and D $1^{\mathrm{NAc}-\mathrm{VM}}\left(m\right.$ Cherry $\left.^{+}\right)$neurons were also analyzed by smFISH. Puncta of Arc of KIf5 were counted within EYFP ${ }^{+}$ or $m$ Cherry ${ }^{+}$cells.

\section{Quantification and statistical analyses}

Experimental data were presented as means \pm SEM, analyzed by SPSS and MATLAB, and plotted by Graphpad Prism. Single-variable comparisons between two groups were analyzed with two-tailed Student's $t$ test. Multiple group comparisons were analyzed using one-way or twoway Analysis of Variance (ANOVA), followed by Bonferroni's post hoc test. In detail, group differences of behavioral tests were detected using repeated measures (RM) ANOVA, followed by Bonferroni's post hoc tests with sessions as a within-subjects factor and CNO treatment or optical stimulation as a between-subjects factor. The electrophysiological data were tested for significance using two-tailed Student's $t$-test, or RM ANOVA, followed by Bonferroni's post hoc tests with current injection as a within-subjects factor and neuronal type as a between-subjects factor. Photometry data were analyzed with two-tailed Student's paired $t$-test for fluorescence of $\Delta \mathrm{F} / \mathrm{F}$. Immunofluorescence data were analyzed by two-tailed Student's $t$-test or one-way ANOVA. FISH data were analyzed by two-tailed Student's $t$-test. The non-normalized data were analyzed with Mann-Whitney U test, Kruskal-Wallis one-way ANOVA on Ranks, or RM ANOVA with Geisser-Greenhouse correction. Full statistical analyses corresponding to each data set are presented in Supplementary information, Table S1.

\section{DATA AVAILABILITY}

All data are available from the corresponding author upon reasonable request. Single-cell RNA sequencing data have been deposited in the Gene Expression Omnibus under accession number PRJNA692326.

\section{CODE AVAILABILITY}

Custom MATLAB codes are available from the corresponding author upon reasonable request.

\section{REFERENCES}

1. Tye, K. M. Neural circuit motifs in valence processing. Neuron 100, 436-452 (2018).

2. Lang, P. J. \& Davis, M. Emotion, motivation, and the brain: reflex foundations in animal and human research. Prog. Brain Res. 156, 3-29 (2006).

3. Fiorillo, C. D. Two dimensions of value: dopamine neurons represent reward but not aversiveness. Science 341, 546-549 (2013).

4. Lammel, S., Ion, D. I., Roeper, J. \& Malenka, R. C. Projection-specific modulation of dopamine neuron synapses by aversive and rewarding stimuli. Neuron 70, 855-862 (2011).

5. Lammel, S. et al. Input-specific control of reward and aversion in the ventral tegmental area. Nature 491, 212-217 (2012).

6. Gangarossa, G. et al. Distribution and compartmental organization of GABAergic medium-sized spiny neurons in the mouse nucleus accumbens. Front. Neural. Circuits 7, 22 (2013).

7. Heiman, M. et al. A translational profiling approach for the molecular characterization of CNS cell types. Cell 135, 738-748 (2008).

8. Gerfen, C. R. et al. D1 and D2 dopamine receptor-regulated gene expression of striatonigral and striatopallidal neurons. Science 250, 1429-1432 (1990).

9. Smith, R. J., Lobo, M. K., Spencer, S. \& Kalivas, P. W. Cocaine-induced adaptations in D1 and D2 accumbens projection neurons (a dichotomy not necessarily synonymous with direct and indirect pathways). Curr. Opin. Neurobiol. 23, 546-552 (2013).

10. Kupchik, Y. M. et al. Coding the direct/indirect pathways by D1 and D2 receptors is not valid for accumbens projections. Nat. Neurosci. 18, 1230-1232 (2015).

11. Gerfen, C. R. \& Surmeier, D. J. Modulation of striatal projection systems by dopamine. Annu. Rev. Neurosci. 34, 441-466 (2011).

12. Soares-Cunha, C., Coimbra, B., Sousa, N. \& Rodrigues, A. J. Reappraising striatal D1- and D2-neurons in reward and aversion. Neurosci. Biobehav. Rev. 68, 370-386 (2016).

13. Lobo, M. K. et al. Cell type-specific loss of BDNF signaling mimics optogenetic control of cocaine reward. Science 330, 385-390 (2010).

14. Heinsbroek, J. A. et al. Loss of plasticity in the D2-accumbens pallidal pathway promotes cocaine seeking. J. Neurosci. 37, 757-767 (2017).

15. Tritsch, N. X. \& Sabatini, B. L. Dopaminergic modulation of synaptic transmission in cortex and striatum. Neuron 76, 33-50 (2012).

16. Richfield, E. K., Penney, J. B. \& Young, A. B. Anatomical and affinity state comparisons between dopamine D1 and D2 receptors in the rat central nervous system. Neuroscience 30, 767-777 (1989).

17. Lobo, M. K. \& Nestler, E. J. The striatal balancing act in drug addiction: distinct roles of direct and indirect pathway medium spiny neurons. Front. Neuroanat. 5, 41 (2011).

18. Hikida, T. et al. Pathway-specific modulation of nucleus accumbens in reward and aversive behavior via selective transmitter receptors. Proc. Natl. Acad. Sci. USA 110, 342-347 (2013).

19. Volkow, N. D. \& Morales, M. The brain on drugs: from reward to addiction. Cell 162, 712-725 (2015).

20. Oleson, E. B., Gentry, R. N., Chioma, V. C. \& Cheer, J. F. Subsecond dopamine release in the nucleus accumbens predicts conditioned punishment and its successful avoidance. J. Neurosci. 32, 14804-14808 (2012).

21. Menegas, W., Akiti, K., Amo, R., Uchida, N. \& Watabe-Uchida, M. Dopamine neurons projecting to the posterior striatum reinforce avoidance of threatening stimuli. Nat. Neurosci. 21, 1421-1430 (2018).

22. Li, C. et al. Toll-like receptor 4 deficiency causes reduced exploratory behavior in mice under approach-avoidance conflict. Neurosci. Bull. 32, 127-136 (2016). 
23. McNaughton, N. \& Corr, P. J. A two-dimensional neuropsychology of defense: fear/anxiety and defensive distance. Neurosci. Biobehav. Rev. 28, 285-305 (2004).

24. Kim, J. et al. Rapid, biphasic CRF neuronal responses encode positive and negative valence. Nat. Neurosci. 22, 576-585 (2019).

25. Yuan, Y. et al. Reward inhibits paraventricular CRH neurons to relieve stress. Curr. Biol. 29, 1243-1251 (2019).

26. Thoeni, S., Loureiro, M., O'Connor, E. C. \& Luscher, C. Depression of accumbal to lateral hypothalamic synapses gates overeating. Neuron 107, 158-172 (2020).

27. Kim, C. K. et al. Molecular and circuit-dynamical identification of top-down neural mechanisms for restraint of reward seeking. Cell 170, 1013-1027 (2017).

28. de Jong, J. W. et al. A neural circuit mechanism for encoding aversive stimuli in the mesolimbic dopamine system. Neuron 101, 133-151 (2019).

29. Gielow, M. R. \& Zaborszky, L. The input-output relationship of the cholinergic basal forebrain. Cell Rep. 18, 1817-1830 (2017).

30. Wall, N. R., Wickersham, I. R., Cetin, A., De La Parra, M. \& Callaway, E. M. Monosynaptic circuit tracing in vivo through Cre-dependent targeting and complementation of modified rabies virus. Proc. Natl. Acad. Sci. USA 107, 2184821853 (2010).

31. Lobo, M. K., Karsten, S. L., Gray, M., Geschwind, D. H. \& Yang, X. W. FACS-array profiling of striatal projection neuron subtypes in juvenile and adult mouse brains. Nat. Neurosci. 9, 443-452 (2006).

32. Lobo, M. K., Cui, Y., Ostlund, S. B., Balleine, B. W. \& Yang, X. W. Genetic control of instrumental conditioning by striatopallidal neuron-specific S1P receptor Gpr6. Nat. Neurosci. 10, 1395-1397 (2007).

33. Lu, K. M., Evans, S. M., Hirano, S. \& Liu, F. C. Dual role for Islet-1 in promoting striatonigral and repressing striatopallidal genetic programs to specify striatonigral cell identity. Proc. Natl. Acad. Sci USA 111, E168-E177 (2014).

34. Tan, K. R. et al. GABA neurons of the VTA drive conditioned place aversion. Neuron 73, 1173-1183 (2012).

35. Bocklisch, C. et al. Cocaine disinhibits dopamine neurons by potentiation of GABA transmission in the ventral tegmental area. Science 341, 1521-1525 (2013).

36. Sun, F. et al. A genetically encoded fluorescent sensor enables rapid and specific detection of dopamine in flies, fish, and mice. Cell 174, 481-496 (2018).

37. Sun, F. et al. Next-generation GRAB sensors for monitoring dopaminergic activity in vivo. Nat. Methods 17, 1156-1166 (2020).

38. Soares-Cunha, C. et al. Nucleus accumbens medium spiny neurons subtypes signal both reward and aversion. Mol. Psychiatry. 25, 3241-3255 (2020).

39. Al-Hasani, R. et al. Distinct subpopulations of nucleus accumbens dynorphin neurons drive aversion and reward. Neuron 87, 1063-1077 (2015).

40. Yang, $H$. et al. Nucleus accumbens subnuclei regulate motivated behavior via direct inhibition and disinhibition of VTA dopamine subpopulations. Neuron $\mathbf{9 7}$, 434-449 (2018).

41. Lafferty, C. K., Yang, A. K., Mendoza, J. A. \& Britt, J. P. Nucleus accumbens cell typeand input-specific suppression of unproductive reward seeking. Cell Rep. 30, 3729-3742 (2020).

42. Xiu, J. et al. Visualizing an emotional valence map in the limbic forebrain by TAIFISH. Nat. Neurosci. 17, 1552-1559 (2014).

43. Yao, Y. et al. Projections from D2 neurons in different subregions of nucleus accumbens shell to ventral pallidum play distinct roles in reward and aversion. Neurosci. Bull. 37, 623-640 (2021).

44. Bromberg-Martin, E. S., Matsumoto, M. \& Hikosaka, O. Dopamine in motivational control: rewarding, aversive, and alerting. Neuron 68, 815-834 (2010).

45. Smith, K. S. \& Berridge, K. C. The ventral pallidum and hedonic reward: neurochemical maps of sucrose "liking" and food intake. J. Neurosci. 25, 8637-8649 (2005).

46. Shimura, T., Imaoka, H. \& Yamamoto, T. Neurochemical modulation of ingestive behavior in the ventral pallidum. Eur. J. Neurosci. 23, 1596-1604 (2006).

47. Panagis, G., Miliaressis, E., Anagnostakis, Y. \& Spyraki, C. Ventral pallidum selfstimulation: a moveable electrode mapping study. Behav. Brain Res. 68, 165-172 (1995).

48. Heinsbroek, J. A. et al. Opposing regulation of cocaine seeking by glutamate and GABA neurons in the ventral pallidum. Cell Rep. 30, 2018-2027 e2013 (2020).

49. Faget, L. et al. Opponent control of behavioral reinforcement by inhibitory and excitatory projections from the ventral pallidum. Nat. Commun 9, 849 (2018).

50. Creed, M., Ntamati, N. R., Chandra, R., Lobo, M. K. \& Luscher, C. Convergence of reinforcing and anhedonic cocaine effects in the ventral pallidum. Neuron $\mathbf{9 2}$, 214-226 (2016).

51. Corbella, B. \& Vieta, E. Molecular targets of lithium action. Acta. Neuropsychiatr. 15, 316-340 (2003)

52. Beaulieu, J. M. et al. A beta-arrestin 2 signaling complex mediates lithium action on behavior. Cell 132, 125-136 (2008)

53. Beaulieu, J. M. et al. Lithium antagonizes dopamine-dependent behaviors mediated by an AKT/glycogen synthase kinase 3 signaling cascade. Proc. Natl. Acad. Sci. USA 101, 5099-5104 (2004).
54. Friedman, E. \& Gershon, S. Effect of lithium on brain dopamine. Nature 243, 520-521 (1973).

55. Achat-Mendes, C., Ali, S. F. \& Itzhak, Y. Differential effects of amphetaminesinduced neurotoxicity on appetitive and aversive Pavlovian conditioning in mice. Neuropsychopharmacology 30, 1128-1137 (2005).

56. Rebecca Glatt, A., St John, S. J., Lu, L. \& Boughter, J. D. Jr Temporal and qualitative dynamics of conditioned taste aversions in C57BL/6J and DBA/2J mice selfadministering LiCl. Physiol. Behav. 153, 97-108 (2016).

57. Pardo-Garcia, T. R. et al. Ventral pallidum is the primary target for accumbens D1 projections driving cocaine seeking. J. Neurosci. 39, 2041-2051 (2019).

58. Baimel, C., McGarry, L. M. \& Carter, A. G. The projection targets of medium spiny neurons govern cocaine-evoked synaptic plasticity in the nucleus accumbens. Cell Rep. 28, 2256-2263 e2253 (2019).

59. Yuan, L., Dou, Y. N. \& Sun, Y. G. Topography of reward and aversion encoding in the mesolimbic dopaminergic system. J. Neurosci. 39, 6472-6481 (2019).

60. Patriarchi, T. et al. Ultrafast neuronal imaging of dopamine dynamics with designed genetically encoded sensors. Science. 360, eaat4422 (2018).

61. Lammel, S. et al. Unique properties of mesoprefrontal neurons within a dual mesocorticolimbic dopamine system. Neuron 57, 760-773 (2008).

62. Refahi, Y. et al. A multiscale analysis of early flower development in Arabidopsis provides an integrated view of molecular regulation and growth control. Dev. Cell. 56, 540-556 (2021).

63. Britt, J. P. et al. Synaptic and behavioral profile of multiple glutamatergic inputs to the nucleus accumbens. Neuron 76, 790-803 (2012).

64. Gunaydin, L. A. \& Kreitzer, A. C. Cortico-basal ganglia circuit function in psychiatric disease. Annu. Rev. Physiol. 78, 327-350 (2016).

65. Nieh, E. H. et al. Inhibitory input from the lateral hypothalamus to the ventral tegmental area disinhibits dopamine neurons and promotes behavioral activation. Neuron 90, 1286-1298 (2016).

66. Ting, J. T., Daigle, T. L., Chen, Q. \& Feng, G. Acute brain slice methods for adult and aging animals: application of targeted patch clamp analysis and optogenetics. Methods Mol. Biol. 1183, 221-242 (2014).

67. Gertler, T. S., Chan, C. S. \& Surmeier, D. J. Dichotomous anatomical properties of adult striatal medium spiny neurons. J. Neurosci. 28, 10814-10824 (2008).

68. Kim, J., Park, B. H., Lee, J. H., Park, S. K. \& Kim, J. H. Cell type-specific alterations in the nucleus accumbens by repeated exposures to cocaine. Biol. Psychiatry 69, 1026-1034 (2011).

69. Tejeda, H. A. et al. Pathway- and Cell-Specific Kappa-Opioid Receptor Modulation of Excitation-Inhibition Balance Differentially Gates D1 and D2 Accumbens Neuron Activity. Neuron 93, 147-163 (2017).

70. Benthall, K. N., Ong, S. L. \& Bateup, H. S. Corticostriatal transmission is selectively enhanced in striatonigral neurons with postnatal loss of Tsc1. Cell Rep. 23, 3197-3208 (2018).

71. Matthews, G. A. et al. Dorsal raphe dopamine neurons represent the experience of social isolation. Cell 164, 617-631 (2016).

72. Qi, J. et al. VTA glutamatergic inputs to nucleus accumbens drive aversion by acting on GABAergic interneurons. Nat. Neurosci. 19, 725-733 (2016).

73. Liu, Z. et al. Dorsal raphe neurons signal reward through $5-\mathrm{HT}$ and glutamate. Neuron 81, 1360-1374 (2014).

74. Li, Y. et al. Serotonin neurons in the dorsal raphe nucleus encode reward signals. Nat. Commun 7, 10503 (2016).

75. Guo, Q. et al. Multi-channel fiber photometry for population neuronal activity recording. Biomed. Opt. Express 6, 3919-3931 (2015).

76. Bavley, C. C. et al. Cocaine- and stress-primed reinstatement of drugassociated memories elicit differential behavioral and frontostriatal circuit activity patterns via recruitment of L-type $\mathrm{Ca}(2+)$ channels. Mol. Psychiatry 25, 2373-2391 (2020).

77. Picelli, S. et al. Full-length RNA-seq from single cells using Smart-seq2. Nat. Protoc. 9, 171-181 (2014).

78. Zhong, S. et al. A single-cell RNA-seq survey of the developmental landscape of the human prefrontal cortex. Nature 555, 524-528 (2018).

79. Ziegenhain, $C$. et al. Comparative analysis of single-cell RNA sequencing methods. Mol. Cell 65, 631-643 e634 (2017).

80. Parekh, S., Ziegenhain, C., Vieth, B., Enard, W. \& Hellmann, I. zUMls-A fast and flexible pipeline to process RNA sequencing data with UMIs. Gigascience. 7, giy059 (2018).

81. Dobin, A. et al. STAR: ultrafast universal RNA-seq aligner. Bioinformatics 29, 15-21 (2013).

82. Butler, A., Hoffman, P., Smibert, P., Papalexi, E. \& Satija, R. Integrating single-cell transcriptomic data across different conditions, technologies, and species. Nat. Biotechnol. 36, 411-420 (2018).

83. Love, M. I., Huber, W. \& Anders, S. Moderated estimation of fold change and dispersion for RNA-seq data with DESeq2. Genome Biol. 15, 550 (2014).

84. Yu, G., Wang, L. G., Han, Y. \& He, Q. Y. clusterProfiler: an R package for comparing biological themes among gene clusters. OMICS 16, 284-287 (2012). 
85. Beier, K. T. et al. Circuit architecture of VTA dopamine neurons revealed by systematic input-output mapping. Cell 162, 622-634 (2015).

86. Xiao, L., Priest, M. F., Nasenbeny, J., Lu, T. \& Kozorovitskiy, Y. Biased oxytocinergic modulation of midbrain dopamine systems. Neuron 95, 368-384 (2017).

\section{ACKNOWLEDGEMENTS}

We thank Dr. Yulong Li (Peking University) for providing the powerful tool for monitoring extracellular DA (AAV-hSyn-DA2m). This research was supported by grants from the National Natural Science Foundation of China (31930046, 31771176, 32171041, 82021002, 3197043), the Shanghai Municipal Science and Technology Major Project (2018SHZDZX01), and National Key R\&D Program of China (2018YFC1004500).

\section{AUTHOR CONTRIBUTIONS}

L.M. and X.L. designed the experiment. Z.L., X.S., C.M., D.C. and X.C. performed the behavioral experiment and contributed to the analysis. Z.L., Q.L., and J.C. performed single-cell transcriptomes, and Q.M.L did bioinformatical analysis. Z.L., Y.L., Y.Z., X.L., R.Y., and J.Z. designed and performed all electrophysiology experiments and processed and analyzed the data. Z.L., C.M., X.C., Y.L., and L.X. performed viral injections, brain preparation, imaging, and analysis. X.C. and C.M. assisted cocaine conditioning and electrophysiology experiments. L.M. and X.L. supervised the project. L.M., X.L., and Z.L. wrote the paper.

\section{COMPETING INTERESTS}

The authors declare no competing interests.

\section{ADDITIONAL INFORMATION}

Supplementary information The online version contains supplementary material available at https://doi.org/10.1038/s41422-021-00588-5.

Correspondence and requests for materials should be addressed to Lan Ma or Xing Liu.

Reprints and permission information is available at http://www.nature.com/ reprints
Open Access This article is licensed under a Creative Commons Attribution 4.0 International License, which permits use, sharing, adaptation, distribution and reproduction in any medium or format, as long as you give appropriate credit to the original author(s) and the source, provide a link to the Creative Commons license, and indicate if changes were made. The images or other third party material in this article are included in the article's Creative Commons license, unless indicated otherwise in a credit line to the material. If material is not included in the article's Creative Commons license and your intended use is not permitted by statutory regulation or exceeds the permitted use, you will need to obtain permission directly from the copyright holder. To view a copy of this license, visit http://creativecommons. org/licenses/by/4.0/.

(C) The Author(s) 2021 